\title{
Object licensing in Fijian and the role of adjacency
}

\author{
Coppe van Urk ${ }^{1}$
}

Received: 11 August 2017 / Accepted: 29 October 2018 / Published online: 14 February 2019

(C) The Author(s) 2019

\begin{abstract}
Fijian displays a crosslinguistically unusual system of differential object marking (DOM) (Alderete 1998; Aranovich 2013). In typical DOM effects, objects higher in animacy and/or definiteness receive additional morphological marking and appear in higher syntactic positions. In Fijian, however, pronoun and proper name objects, although higher on standard DOM hierarchies, must remain verb-adjacent and surface without an article. This paper argues that this pattern arises because pronoun and proper name objects undergo morphological merger with the verb at PF, which allows a nominal to escape the Case Filter (Levin 2015; Branan 2017). I present evidence that, in contrast, common noun objects in Fijian are structurally reduced, and so do not need Case licensing. As a result, Fijian provides support for an approach to DOM in which objects higher in definiteness/animacy have an additional Case licensing need (e.g. Massam 2001; Danon 2006; Ormazabal and Romero 2013; Kalin 2018), and against theories that rely exclusively on differences in syntactic position or overt marking.
\end{abstract}

Keywords Differential object marking $\cdot$ Fijian $\cdot$ Adjacency $\cdot$ Case $\cdot$ Licensing

\section{Introduction}

Many researchers working on the syntax of Fijian ${ }^{1}$ have noted that it has a crosslinguistically unusual pattern of differential object marking (e.g. Dixon 1988; Alderete

\footnotetext{
${ }^{1}$ Abbreviations for Fijian: $1 / 2 / 3=1 \mathrm{st} / 2 \mathrm{nd} / 3 \mathrm{rd}$ person, ART $=$ article, $\mathrm{C}=$ complementizer, $\mathrm{CAUS}=$ causative, $\mathrm{DIR}=$ directional, $\mathrm{DU}=$ dual, $\mathrm{EXCL}=$ exclusive, $\mathrm{FUT}=$ future, $\mathrm{HAB}=$ habitual, $\mathrm{INCL}=$ inclusive, $\mathrm{N}=$ common noun, $\mathrm{PAUC}=$ paucal, $\mathrm{PL}=$ plural, $\mathrm{POSS}=$ possessive, $\mathrm{PR}=$ pronoun $/$ proper name, $\mathrm{PROG}=$ progressive, $\mathrm{PST}=$ past, $\mathrm{RP}=$ recent past, $\mathrm{SG}=$ singular, $\mathrm{TR}=$ transitive.

C. van Urk

c.vanurk@qmul.ac.uk

1 School of Languages, Linguistics, and Film, Queen Mary University of London, Mile End Rd, E1 4NS London, United Kingdom
} 
1998; Aranovich 2013). Fijian pronoun and proper name objects must remain immediately adjacent to the verb and surface without their article ko/o (1a). In contrast, common noun objects vacate the VP, and appear with the article for common nouns, na (1b).

Two types of objects in Fijian:
a. e a [vp kau-ti au/Jone mai] ko Eroni. 3SG PST bring-TR.PR 1SG/Jone DIR ART.PR Eroni 'Eroni brought me/Jone.'
b. e a [vp kau-ta__ mai] na ilokoloko ko Eroni. 3SG PST bring-TR.N DIR ART.N pillow ART.PR Eroni 'Eroni brought the pillow(s).'

At first glance, the pattern in (1a-b) seems to go against familiar generalizations about differential object marking (DOM) (e.g. Comrie 1989; Bossong 1991; Aissen 2003). DOM patterns crosslinguistically involve an additional marker or a higher syntactic position for objects higher in animacy and definiteness. In Pitjantjatjara, for example, pronoun and proper name objects carry accusative case marking, while common nouns do not $(2 \mathrm{a}-\mathrm{c})$. A similar pattern is found with the dative marker $\grave{a}$ in Corsican $(3 \mathrm{a}-\mathrm{b})$.

(2) Only pronoun/proper name objects have accusative in Pitjantjatjara:
a. Tjitji-ngku Billy-nya nya-ngu. child-ERG Billy-ACC see-PAST
'The child saw Billy.'
b. Tjitji-ngku ngayu-nya nya-ngu. child-ERG 1SG-ACC see-PAST
'The child saw me.'
c. Billy-lu tjitji nya-ngu. Billy-ERG child see-PAST 'Billy saw the child.'

(Pitjantjatjara; Bowe 1990:10-11)

(3) Only pronoun/proper name objects marked with à in Corsican:
a. Vegu chè tù preferisci più à Peneloppe chè à mè. see.1SG that you prefer more DAT Peneloppe than DAT me 'I see, you prefer Peneloppe rather than me.'
b. Vigu (*à) l'-omu. see.1SG DAT DET-man 'I see the man.'

(Corsican; Neuburger and Stark 2014:366-367)

In this paper, I argue that the Fijian pattern is nonetheless a genuine instance of DOM (see also Aranovich 2013). I present evidence that the adjacency of pronoun/proper name objects to the verb reflects a requirement that such objects satisfy licensing through adjacency with the verb (Levin 2015; Branan 2017; cf. Stowell 1981; Adger 2000; Ackema and Neeleman 2003). An important piece of evidence for this proposal comes from the observation that a pronoun/proper name can be marked as an object of a higher verb across a clause boundary, as long as the verb and nominal are adjacent. A pronoun or proper name that is initial in an embedded 
clause, like the $w h$-pronoun in $(4 \mathrm{a}-\mathrm{b})$, can be treated as the object of the embedding verb, as evident in the possibility of article omission and the morphology of the verb. Importantly, this pattern is only possible if nothing intervenes linearly between the higher verb and the pronoun/proper name (4b).

Object marking is possible across CP boundary with linear adjacency:
a. au kila-i [CP cei e a rai-ca na cava].
1SG know-TR.PR who 3SG PST see-TR.N ART.N what
'I know who saw what.'
b. *e kila-i ko Eroni [cP cei iko a rai-ca].
'Eroni knows who you saw.' 3SG know-TR.N ART.PR Eroni who 2SG PST see-TR.PR

Like the DOM pattern, this effect is crosslinguistically unusual. It resembles raisingto-object or long-distance agreement (e.g. Massam 1985; Polinsky and Potsdam 2001; Branigan and MacKenzie 2002), but is unique in its sensitivity to linear adjacency.

To capture this adjacency requirement on Fijian pronouns and proper names, I propose that such objects undergo an operation of morphological merger with a verb at PF (Levin 2015; Branan 2017), Embick and Noyer's (2001) Local Dislocation, as in (5).

$$
\begin{aligned}
& \text { Local Dislocation of pronoun/proper name object: } \\
& {\left[{ }_{v \mathrm{P}} \mathrm{V}+v[\text { Jone }]\right] \rightarrow\left[{ }_{v \mathrm{P}} \mathrm{V}+v+\right.\text { Jone }}
\end{aligned}
$$

As a result of this operation, pronouns and proper names become part of the extended verbal projection and so escape the Case Filter (see also Baker 1988; Levin 2015). In contrast, I argue that common noun objects in Fijian are structurally reduced (they do not encode number, definiteness or host numerals), and so do not require Case licensing. In this approach, the Fijian pattern arises because pronoun/proper name objects have a licensing need, the same need that is satisfied by accusative case in Pitjantjatjara or dative case in Corsican.

These Fijian facts provide evidence that differential object marking cannot exclusively reflect object shift or the presence of additional case morphology on objects higher in definiteness/animacy. Instead, Fijian DOM suggests an approach that posits an abstract difference in the structure of such objects, such that they have a licensing need absent on other nominals (e.g. Massam 2001; Danon 2006; Ormazabal and Romero 2013; Kalin 2018). In this kind of perspective, the form this Case licensing takes may in principle vary across languages. In many languages, objects higher in definiteness/animacy surface with an adposition or additional case marking, as in Pitjantjatjara or Corsican. In other languages, like Senaya (Kalin 2018), DOM involves an additional agreement process. And, in Fijian, as I will show, DOM takes the form of an adjacency requirement, because morphological merger with a verb allows an object to escape the Case Filter.

Another contribution of the paper is to provide evidence against the idea that Fijian is a (partial) pronominal argument language (Jelinek 1984; Baker 1988), as in Schütz and Nawadra (1972), Alderete (1998), Aranovich (2013), and Schütz (2014). 
In this analysis, the Fijian DOM pattern arises because common nouns are not true objects of the verb, but dislocated phrases, co-indexed with a clitic on the verb. This approach posits that Fijian is different from other pronominal argument languages in that pronouns and proper names can be true objects, so that they are able to surface in the complement position of the verb. The novel evidence presented here also shows that partial polysynthesis is not behind the Fijian pattern. The facts in (4a-b) demonstrate that Fijian DOM does not reflect a difference between base-generation and dislocation, since the difference between pronouns/proper names and common nouns is found even in a derived environment. One of the implications of the analysis then is that it may not be necessary to admit the possibility of partial pronominal argument languages into the grammar (see also Siewierska 2001).

The paper is structured as follows. Section 2 describes verb-initial syntax in Fijian, arguing for a VP-fronting analysis that provides us with an understanding of how to diagnose object positions. In Sect. 3, I outline the differential object marking pattern and show that pronouns and proper names appear without their article and are in a position lower than other objects, immediately adjacent to the verb. Section 4 presents novel evidence showing that the DOM pattern is about adjacency, since object marking is possible across a clause boundary, as long as the linear adjacency requirement is met. In Sect. 5, I develop an analysis of Fijian DOM in which pronouns and proper names escape the Case Filter through morphological merger with the verb at PF (Levin 2015; Branan 2017), providing evidence for an approach to DOM based on licensing (e.g. Danon 2006; Ormazabal and Romero 2013; Kalin 2018). I also discuss other DOM patterns that may be based on adjacency, found in related Oceanic languages. Finally, in Sect. 6, I show that the facts presented here argue against an analysis of Fijian as a partial pronominal argument language, as in Schütz and Nawadra (1972), Alderete (1998), Aranovich (2013), and Schütz (2014).

\section{Verb-initial word order in Fijian}

I will start by arguing for a VP-fronting account of verb-initial word order in Fijian, similar to other VP-fronting accounts of VOS order for Oceanic languages (e.g. Massam 2001; Medeiros 2013; Collins 2017), which will set the stage for a discussion of object marking in Fijian. Identifying a fronted VP constituent will allow us to show that pronoun and proper name objects remain low, because they must be inside this fronted VP (see also Alderete 1998; Aranovich 2013). The argument for VP-fronting comes from the distribution of preverbal and postverbal particles, which "mirror" around the verb (see also Rackowski and Travis 2000 and Massam 2010 for similar observations for other Austronesian languages). We will see that capturing this observation requires recognizing a VP constituent before the subject, within which postverbal particles can right-attach.

\subsection{Fijian word order and the distribution of preverbal and postverbal particles}

Fijian is an Oceanic language spoken in Fiji by around 400,000 speakers. This paper presents original data from Standard Fijian, an Eastern Fijian dialect, collected in a field methods class at Queen Mary and individual elicitation sessions with two speakers. 
Fijian is generally predicate-initial. Unmarked sentences in Fijian alternate between VOS and VSO order (e.g. Dixon 1988; Aranovich 2013), as shown in (6a-b). ${ }^{2}$

\section{VOS and VSO word order are unmarked:}

a. e a diri-ka na niu ko Eroni.

3SG PST crack-TR.N ART.N coconut ART.PR Eroni 'Eroni cracked the coconut.'

b. e na diri-ka ko Eroni na niu.

3SG FUT crack-TR.N ART.PR Eroni ART.N coconut

'Eroni will crack the coconut.'

Both VOS and VSO word orders appear to be neutral. For example, both answers in $(7 b-c)$ are felicitous responses to a broad focus question like $(7 a) .^{3}$

\section{VOS and VSO are both informationally neutral:}

a. A: na cava e yaco?

ART.N what 3SG happen

'What is happening?'

b. B: e a diri-ka na niu ko Jone.

3SG PST crack-TR.N ART.N coconut ART.PR Jone

'Jone cracked the coconut.'

c. B: e a diri-ka ko Jone na niu.

3SG PST crack-TR.N ART.PR Jone ART.N coconut

'Jone cracked the coconut.'

I will argue for a VP-fronting analysis of verb-initial word order in Fijian (see also Massam 2001; Medeiros 2013; Collins 2017 on other Oceanic languages). Following Sabel (2011), I show that VOS/VSO word order should not be derived through $\mathrm{V}$-movement. The main argument for this conclusion comes from the distribution of preverbal and postverbal particles, which mirror around the verb, and provide evidence for an initial VP constituent. Identifying this fronted VP will be important later to demonstrate that pronoun and proper name objects remain low, while common noun objects vacate the VP, in a manner reminiscent of Massam's (2001) analysis of Niuean.

Let us first examine the distribution of preverbal particles. Fijian has a set of particles that typically must appear before the main predicate of the clause. These include

\footnotetext{
${ }^{2}$ Schütz (2014) argues against classifying Fijian as a verb-initial language on the basis of the polysynthetic analysis described in Sect. 6. He suggests that, if the subject/object agreement markers are taken to represent the true subject and object, Fijian is SVO. Since I will present data that argues against this polysynthetic approach, I set this view aside here.

${ }^{3}$ In texts, it is difficult to detect a preferred order. In the corpus gathered by Dixon (1988), intransitive sentences or transitive sentences in which one or both of the subject and object is dropped are far more common. He estimates that "only about 2 or 3 percent of clauses are likely to have A and O NPs" (242). Among those, VSO and VOS seem to be equally distributed. As noted by Dixon (1988), however, VOS word order is more common in elicitation, and so is sometimes interpreted as the default order. VSO sentences seem to be more common if the object is inanimate and there is no potential for ambiguity. This forms an interesting contrast with tendencies in Mayan VSO/VOS languages, as recently discussed by Clemens and Coon (2018).
} 
a set of subject clitics (8a), as well as tense/aspect particles like $a$ (past tense) and dau (habitual) (8b-c). See Schütz (2014: ch. 5) for an extensive overview.

Preverbal particles in Fijian:

a. au vosa.

1SG speak

'I speak.'

b. e a diri-ka na niu ko Eroni.

3SG PST crack-TR.N ART.N coconut ART.PR Eroni

'Eroni cracked a coconut.'

c. au dau vosa.

1SG HAB talk

'I always talk.'

These particles occur in a fixed order for the most part, reflecting left-to-right scope. For example, tense particles must precede aspect particles, as demonstrated in (9a-b) for past tense $a$ and habitual $d a u$.

(9) Preverbal particles scope left-to-right:

a. au a dau moce.

1SG PST HAB sleep

'I used to always sleep.'

b. *au dau a moce.

1SG HAB PAST sleep

'I used to always sleep.'

The behavior of preverbal particles can be contrasted with particles that appear after the verb. Like a number of other Austronesian languages (see, for instance, Rackowski and Travis 2000 and Massam 2010), Fijian has a class of particles that must appear after the predicate, which encode direction, manner, as well as some aspectual distinctions, among other things. These include the progressive marker tiko (10a), the adverbial vaka (10b), and the directional particle mai (10c). See Schütz (2014: ch. 18) for a more detailed overview.

Postverbal particles in Fijian:

a. e a moce tiko.

3SG PST sleep PROG

'S/he was sleeping.'

b. kerau a taubale vaka tiko.

1EXCL.DU PST walk together PROG

'We were walking together.'

c. sa kau-ta mai na ilokoloko ko Eroni.

RP bring-TR.N DIR ART.N pillow ART.PR Eroni

'Eroni just brought the pillows.'

All such postverbal particles must precede the subject, as demonstrated for the progressive marker tiko in (11a-b) and the directional particle mai in $(11 \mathrm{c}-\mathrm{d})$. 
(11) Postverbal particles must precede the subject:

a. e a moce tiko ko Eroni.

3SG PST sleep PROG ART.PR Eroni

'Eroni was sleeping.'

b. *e a moce ko Eroni tiko.

3SG PST sleep ART.PR Eroni PROG

'Eroni was sleeping.'

c. e kau-ta mai o Koini na ika.

3SG bring-TR.N DIR ART.PR Koini ART.N fish

'Koini brought fish.'

d. *e kau-ta o Koini mai na ika.

3SG bring-TR.N ART.PR Koini DIR ART.N fish

'Koini brought fish.'

Preverbal particles, like postverbal particles, appear in a fixed order (see also Milner 1972:94 and Schütz 2014:166). As Rackowski and Travis (2000) demonstrate for similar elements in Malagasy (see also Massam 2010 on Niuean), postverbal particles are ordered right-to-left, with particles that scope higher appearing further to the right. This is demonstrated for a range of particles in $(12 \mathrm{a}-\mathrm{d}){ }^{4}$

Postverbal particles appear to show inverted order:

a. kerau a taubale vata tale.

1EXCL.DU PST walk together again

'We walked together again.'

b. *kerau a taubale tale vata.

1EXCL.DU PST walk again together

'We walked together again.'

c. keitou a tu cake tiko.

1EXCL.PC PST stand up PROG

'We were standing up.'

d. *keitou a tu tiko cake.

1EXCL.PC PST stand PROG up

'We were standing up.'

In essence then, preverbal and postverbal particles "mirror" around the verb. As discussed by several authors working on similar patterns (Rackowski and Travis 2000; Massam 2010; Sabel 2011), this observation suggests that preverbal particles attach on the left, while postverbal particles must end up attached on the right. Leftattachment yields left-to-right scope, because particles that attach higher will be further on the left. Conversely, right-attachment produces right-to-left scope. Note that it does not matter for the purposes of this conclusion whether we take these particles to instantiate functional heads in the extended projection of the verb or adverbial modifiers.

\footnotetext{
${ }^{4}$ In (12a-b), vata is in the scope of tale, so that (12a) has the reading where walking together is the repeated action. For (12c-d), I assume that directional particles attach lower than progressive aspect, which takes scope over the whole event description.
} 


\subsection{Consequences for the analysis of verb-initial word order}

As Sabel (2011) points out, the conclusion about Fijian particles described above presents a problem for an approach to verb-initial word order based on movement of the verb to a clause-initial position. To see what the issue is, consider the derivation of an example with multiple postverbal particles and an overt subject, like (13).

$$
\begin{aligned}
& \text { e a tu cake tiko o r Koini. } \\
& \text { 3SG PST stand up PROG ART.PR Koini } \\
& \text { 'Koini was standing up.' }
\end{aligned}
$$

A V-movement approach must posit leftward movement of $\mathrm{V}$ across $\mathrm{S}$, crossing the position of the subject. We could suggest, for instance, that the verb moves to a projection FP just below Tense, but above the position of postverbal particles and the subject (14).

A leftward movement analysis of verb-initial word order:

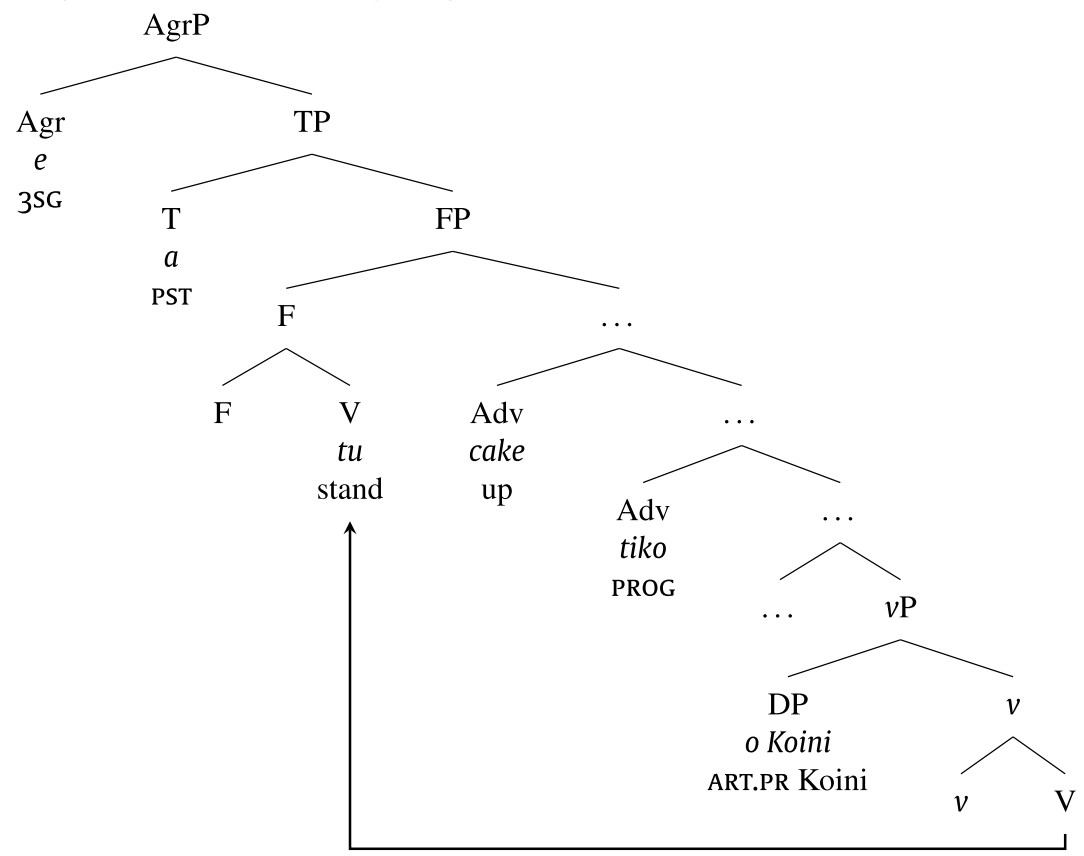

But an analysis like (14) runs into a clear problem in accounting for the behavior of multiple postverbal particles. In order for the subject to reside in a leftward specifier, it must be assumed that postverbal particles reside higher. However, this view must treat postverbal particles like cake and tiko as left-adjoined elements. But left-attachment predicts the wrong scope, as evident in the tree above. Note that we cannot take postverbal particles to be part of the verbal complex, picked up as suffixes through successive applications of head movement. As we will see in Sect. 3, 
postverbal particles come after pronoun/proper name objects, which can be shown not to be incorporated, at least not in the narrow syntax..$^{5}$

The behavior of preverbal and postverbal particles then requires a different view of Fijian word order. Following Aranovich (2013), I suggest that postverbal particles are in fact generated below the subject, and right-adjoin in the verbal domain, which I will refer to as VP for convenience (although we will see reasons to think that it is a larger constituent). This idea also fits well with the observation that postverbal particles, when compared to preverbal particles, tend to contribute meanings that are encoded lower in the clause, such as manner and direction.

We can then derive the order of postverbal particles relative to the subject through VP-fronting. A VP constituent containing all postverbal particles moves to the specifier of a projection FP just below the tense-aspect material contributed by preverbal particles, but above the position of the subject. This analysis is schematized in (15).

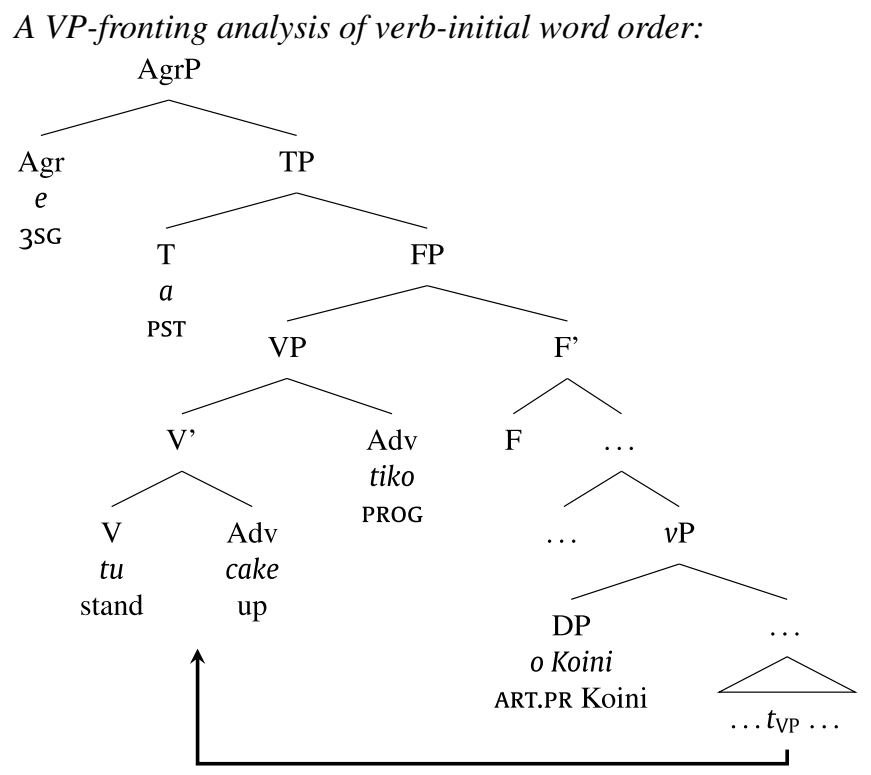

A VP-fronting analysis explains why postverbal particles must appear before the subject. In addition, it accommodates the observation that postverbal particles scope right-to-left, as evident in (15), because it provides right-adjunction sites that precede the subject inside the fronted VP.

Although I adopt the syntax in (15), it is worth noting that there are a variety of other ways in which postverbal particles could end up right-attached. One option is to assume successive phrasal movement, or roll-up movement, which picks up postverbal particles (as in Rackowski and Travis 2000). We could also treat verb-initial order

\footnotetext{
${ }^{5}$ It might be possible to maintain a roll-up V-movement analysis if Local Dislocation were allowed to apply in the course of derivation, but crucially after head movement (see the discussion of causatives in Sect. 3.3 in particular). One issue that this approach runs into, though, is how to distinguish between suffixes on the verb, which are always before pronouns and proper name objects, and postverbal particles, which follow these objects.
} 
as base-generated, with the subject residing in a rightward specifier above all postverbal particles. Both of these options are fully compatible with the syntax I will propose for objects. The key takeaway from this discussion is only that postverbal particles diagnose a VP constituent that is initial in the clause. With this understanding of Fijian verb-initial syntax in place, we can look at how VP-fronting interacts with the placement of objects. In the next section, we will see that pronoun/proper name objects remain inside the fronted VP, and so must be low in the clause.

\section{Three types of objects in Fijian}

In this section, I introduce the problem of differential object marking in Fijian. We will see that Fijian morphologically distinguishes between three types of objects: pronouns/proper names, common nouns, and incorporated nouns. The distinction between pronouns/proper names and common nouns represents a differential object marking pattern, but it will be useful to compare it to the behavior of incorporated nouns. In an apparent reversal of well-known DOM patterns, objects higher in definiteness/animacy appear without an article and must remain in a lower syntactic position. Specifically, pronoun and proper name objects must be immediately adjacent to the verb, before postverbal particles, and so inside the fronted VP described above.

\subsection{Pronoun/proper name objects appear without an article}

Let me focus first on the morphological side of differential object marking. DOM in Fijian is associated both with morphological reflexes on the object itself as well as on the verb.

Fijian verbs distinguish between three types of objects in the morphology of the transitive suffix (Dixon 1988; Alderete 1998; Aranovich 2013). Transitive verbs appear with the transitive suffix $-\mathrm{Ca} / \mathrm{C} i$ (or the long alternates -Caki/-Caka). ${ }^{6}$ If the object is a common noun with the article $n a$, then the verb has the $-\mathrm{Ca}$ suffix, as in (16a). If the object is a pronoun or proper name, then the suffix is - $C i$ (16b). In addition to this, the bare form of the verb may appear before a common noun without article, (16c), in what I will analyze as noun incorporation, following Alderete (1998) and Aranovich (2013).

Three types of objects in Fijian:

a. e a kau-ta mai na ilokoloko ko Eroni. 3SG PST bring-TR.N DIR ART.N pillow ART.PR Eroni

'Eroni brought the pillow(s).'

b. e a kau-ti au mai ko Eroni.

3SG PST bring-TR.PR 1SG DIR ART.PR Eroni

'Eroni brought me.'

c. e dau kau ilokoloko tu ga mai ko Eroni. $^{7}$

3SG HAB bring pillow always DIR ART.PR Eroni

'Eroni always brings pillows.'

\footnotetext{
${ }^{6}$ The consonant used depends on the verb and seems to be idiosyncratically determined (though see Arms 1974 for some apparently systematic correspondences).
} 
As noted above, the DOM pattern also has a morphological reflex on the objects themselves. First of all, the two classes of nominals that participate in DOM are distinguished by the article they appear with. Fijian has two articles, one for pronouns and proper names and one for common nouns. ${ }^{8}$ We can see this with subjects, for example. Pronoun and proper name subjects appear with the article ko/o $(17 \mathrm{a}-\mathrm{b})$.

Pronoun/proper name subjects appear with article ko/o:
a. e a rai-ca na koli ko Eroni.
3SG PST see-TR.N ART.N dog ART.PR Eroni
'Eroni saw the dog.'
1SG HAB talk ART.PR 1SG
'I always talk.'
b. au dau vosa ko yau.

Common noun subjects are accompanied by the article na (18a-b).

\section{Common noun subjects appear with article na:}

a. e a rai-ca na kolina gone.

3SG PST see-TR.N ART.N dog ART.N child

'The child saw the dog.'
b. e a rai-ci Eroni na koli.
3SG PST see-TR.PR Eroni ART.N dog
'The dog saw Eroni.'

The most natural translation of $n a$ is often as a definite article (see also Schütz 2014), but $n a$ should not be viewed as encoding definiteness, as discussed in more detail in Sect. 5.2.

As already alluded to, the articles $n a$ and $k o / o$ diverge when it comes to objects of transitive verbs. Common noun objects must combine with the article na, just like subjects, so that na can appear on a subject and object at the same time:

Article na must appear on object of transitive:
a. e a rai-ca na koli na gone.
3SG PST see-TR.N ART.N dog ART.N child
'The child saw the dog.'
b. *e a rai-ca koli ko Eroni.
3SG PST see-TR.N dog ART.PR Eroni
'Eroni saw the dog.'

The article na may only be omitted in cases of noun incorporation, in which case the verb must be in the bare form. In contrast, a pronoun or proper name object cannot

\footnotetext{
${ }^{7}$ I gloss the combination of $t u$ and $g a$ as "always," because these particles frequently appear together and it is not clear to me what meaning is contributed by each element. See Schütz (2014) for discussion of how $g a$ combines with a range of other particles and the resulting interpretations.

${ }^{8}$ Here and throughout I will use the term "article" to refer to these morphemes, as is common practice in Fijian linguistics. As we will see, however, the distribution of $n a$ and $k o / o$ is more complex and I will analyze them as different functional heads in the extended nominal projection. Specifically, I will suggest that $k o / o$ is an instance of $\mathrm{K}$, while $n a$ is a lower head, $n$.
} 
appear with its article at all. The article ko/o is obligatorily absent on pronoun and proper name objects $(20 \mathrm{a}-\mathrm{b})$, regardless of the morphology of the verb.

Article must be omitted on a pronoun/proper name object:

a. e a rai-ci Eroni na koli. 3SG PST see-TR.PR Eroni ART.N dog 'The dog saw Eroni.'

b. *e a rai-ci ko Eroni na koli. 3SG PST see-TR.PR ART.PR Eroni ART.N dog 'The dog saw Eroni.'

Such morphological differences between pronouns and proper names on the one hand and common nouns on the other are not uncommon in Fijian. Some prepositions morphologically distinguish the two classes of nominals as well. The preposition vei/vua ('to'), for example, comes in two forms depending on the type of object (21a-b). ${ }^{9}$

Choice of vei/vua varies according to type of object:

a. e a sali-a ko Eroni na yaqona vei Jakope.

3SG PST give-TR.N ART.PR Eroni ART.N kava to.PR Jacob 'Eroni gave kava to Jacob.'

b. e a sali-a ko Eroni na kakaua vua na koli. 3SG PST give-TR.N ART.PR Eroni ART.N food to.N ART.N dog 'Eroni gave food to the dog.'

I propose that the morphological differences between pronouns/proper names and common nouns in object position represents a system of differential object marking (see also Aranovich 2013), based on definiteness. Pronouns and proper names are usually considered to be the nominals highest in referentiality, since they are inherently definite and most commonly refer to humans (e.g. Silverstein 1976; Dixon 1979). The Fijian pattern seems to be based on definiteness, and not humanness or animacy, because place names are treated like other proper names, as in $(22 \mathrm{a}-\mathrm{b}) .^{10}$

\section{Place names are treated like other proper names:}
a. au rai-ci Viti.
1SG see-TR.PR Fiji
'I saw Fiji.'
b. *au rai-ca na Viti.
1SG see-TR.N ART.N Fiji
'I saw Fiji.'

In Sect. 5, I argue that the difference in definiteness between pronouns/proper names and common nouns is reflected structurally in Fijian. Specifically, I will propose that pronouns and proper names are associated with a full DP structure, while Fijian common nouns are structurally reduced and lack a definiteness layer altogether.

\footnotetext{
${ }^{9}$ As Dixon (1988) notes, the article ko/o is always omitted after prepositions also.

${ }^{10} \mathrm{My}$ thanks to an anonymous reviewer for pointing out this argument.
} 
What is unusual in Fijian is that the objects higher in definiteness appear without a morpheme, since pronouns and proper names surface without the article ko/o. An apparent crosslinguistic generalization about DOM otherwise is that objects higher in definiteness or animacy appear with an additional morpheme, such as a case marker or a preposition. In the next section, I show that, in addition to this, pronoun and proper name objects must be in a lower position than common nouns, in that they must remain VP-internal.

\subsection{Pronoun/proper name objects remain low}

The second surprising property of differential object marking in Fijian is that pronoun and proper name objects must remain VP-internal, like incorporated nouns, while common nouns surface VP-externally. This positional difference is again unexpected from the perspective of crosslinguistic patterns of DOM, since objects higher on DOM hierarchies tend to occur in higher positions.

To see that there are multiple object positions in Fijian, we can make use of the postverbal particles discussed in Sect. 2. As outlined there, such particles mark the edge of a fronted verb phrase constituent (see also Aranovich 2013). We can use them to investigate the position of an object in VOS word order. Note, first of all, that pronouns/proper names and common nouns differ in whether they permit both VOS and VSO. As shown in (23a-b), repeated from (6a) and (6b), common noun objects may follow or precede the subject.

Common noun objects permit VSO/VOS:
a. e a diri-ka na niu ko Eroni.
3SG PST crack-TR.N ART.N coconut ART.PR Eroni
'Eroni cracked the coconut.'
b. e na diri-ka ko Eroni na niu.
3SG FUT crack-TR.N ART.PR Eroni ART.N coconut
'Eroni will crack the coconut.'

Pronoun and proper name objects are different: they must occur in VOS order (24a-b).

Pronoun/proper name objects only allow VOS:
a. e a cage-ti au ko Eroni. 3SG PST kick-TR.PR 1SG ART.PR Eroni 'Eroni kicked me.'
b. *e a cage-ti ko Eroni (ko) au. 3SG PST kick-TR.PR ART.PR Eroni ART.PR $1 \mathrm{SG}$ 'Eroni kicked me.'

In fact, pronouns/proper name objects must remain inside the fronted VP, as revealed by their position relative to postverbal particles. A pronoun/proper name object always surfaces immediately adjacent to the verb, preceding any postverbal particles, such as the directional particle mai in (25a-b). 
Pronouns/proper names must be adjacent to the verb:
a. e a [vp kau-tii au mai] ko Eroni. 3SG PST bring-TR.PR 1SG DIR ART.PR Eroni 'Eroni brought me.'
b. *e a [vP kau-ti/ta mai] (ko) au ko Eroni. 3SG PST bring-TR.PR/TR.N DIR ART.PR 1SG ART.PR Eroni 'Eroni brought me.'

Common nouns show exactly the opposite behavior, even in VOS order. A common noun object must follow any postverbal particles and cannot appear before them $(26 a-b)$.

\section{Common nouns follow postverbal particles:}
a. e a [vp kau-ta mai] na ilokoloko ko Eroni. 3SG PST bring-TR.N DIR ART.N pillow ART.PR Eroni 'Eroni brought the pillows.'
b. *e a [vp kau-ta (na) ilokoloko mai] ko Eroni. 3SG PST bring-TR.N ART.N pillow DIR ART.PR Eroni 'Eroni brought the pillows.'

The behavior of common noun objects is found also with other categories of internal arguments. PP and CP objects must always vacate the VP, regardless of how they are ordered relative to the subject. The PP argument of vosa ('talk'), for example, must appear after postverbal particles (27a-b). As (27a) shows, such arguments may still precede the subject, like common noun objects.

$P P$ arguments must vacate the VP:

a. e a [vp vosa tiko] vei Jone ko Eroni. 3SG PST talk PROG to.PR Jone ART.PR Eroni 'Eroni talked to Jone.'

b. *e a [vp vosa vei Jone tiko] ko Eroni. 3SG PST talk to.PR Jone PROG ART.PR Eroni 'Eroni talked to Jone.'

Complement clauses also have to appear after postverbal particles (28a-b). ${ }^{11}$

$C P$ arguments must vacate the VP:
a. au [vP kila-a tiko] [CP ni o iko vuku]. 1SG think-TR.N PROG C ART.PR 2SG smart 'I am thinking that you are smart.'
b. *au [vP kila-a [CP ni vuku ko Eroni] tiko]. 1SG know-TR.N C smart ART.PR Eroni PROG 'I am thinking that Eroni is smart.'

\footnotetext{
${ }^{11}$ Unlike other arguments, complement clauses must be in VSO order, and cannot precede the subject. Complement clauses then presumably must undergo an independent extraposition operation.
} 
Like the article omission pattern, this positional difference appears to go against crosslinguistic DOM tendencies. In other languages in which DOM involves a difference in object position, objects that are higher in definiteness/animacy appear in a higher position. For example, Baker and Vinokurova (2010) show that, in Sakha, objects with accusative case must be higher than unmarked objects, as diagnosed by their position relative to adverbs $(29 \mathrm{a}-\mathrm{b})$.

Sakha accusative objects precede adverbs, while unmarked objects follow:

a. Masha salamaat-*(y) türgennik sie-te.

Masha porridge-ACC quickly eat-PAST.3SG

'Masha ate the porridge quickly.'

b. Masha türgennik salamaat-(\#y) sie-te.

Masha quickly porridge-ACC eat-PAST.3SG

'Masha ate porridge quickly.'

(Sakha; Baker and Vinokurova 2010:602)

Some languages even distinguish objects exclusively through position. In Dutch, nonspecific indefinites must be lower than other objects. A non-specific indefinite can only follow an adverb like morgen ('tomorrow') (30a-b), while other objects can both precede and follow (30c-d). (These are the author's judgements, but see also Zwart 2011: ch. 4).

Non-specific indefinites in Dutch must follow adverbs:

a. Ik ga morgen boeken lezen.

I go tomorrow books read

'I will read books tomorrow.'

b. *Ik ga boeken morgen lezen.

I go books tomorrow read

'I will read books tomorrow.'

c. Ik ga dat boek morgen lezen.

I go that book tomorrow read

'I will read that book tomorrow.'

d. Ik ga morgen dat boek lezen.

I go tomorrow that book read

'I will read that book tomorrow.'

(author's judgements)

Both facts about morphological marking and syntactic position then diverge from apparently well-established crosslinguistic generalizations about DOM. In Fijian, pronouns and proper names, while higher in definiteness and animacy, are distinguished by the omission of a morpheme and appear in a lower position. As a consequence, I will argue that the Fijian facts provide evidence against approaches to DOM that are exclusively about additional case marking or object shift.

Before proceeding to my proposal it is important to discuss an alternative analysis of this pattern, which says that pronouns and proper names incorporate into the verb. I will show, following Aranovich (2013), that pronouns and proper names do not undergo noun incorporation, but instead reside in an argument position, such that we still need an explanation of the DOM pattern. 


\subsection{Pronouns and proper names are not incorporated}

Some noun incorporation languages allow pronouns and proper names to incorporate alongside other nouns. Inuktitut, for example, permits incorporation both of nouns, pronouns, and proper names $(31 \mathrm{a}-\mathrm{b})$.

Inuktitut allows incorporation of pronouns/proper names:

a. iglu-jjua-liu-lauq-tuq

house-big-make-PAST-DECL.3SG

'S/he made a big house.'

b. alaana-u-quuji-juq

Alana-COP-seem-DECL.3SG

'She looks like Alana.'

(Compton and Pittman 2010:2168)

As previously mentioned, Fijian has a productive process of noun incorporation (Alderete 1998; Aranovich 2013). Incorporated nouns appear in the fronted VP, before any postverbal particles, without the article $n a(32 \mathrm{a}-\mathrm{c})$.

Bare noun object must appear before postverbal particles:

a. e dau [vp kau ilokoloko tu ga mai] ko Eroni.

3SG HAB bring pillow always DIR ART.PR Eroni

'Eroni always brings pillows.'

b. *e dau [vp kau(-ta)_ tu ga mai] ilokoloko ko Eroni. 3SG HAB bring(-TR.N) always DIR pillow ART.PR Eroni

'Eroni always bring pillows.'

c. eratou a caka iri.

3PC PST make fan

'They made fans.'

These structures appear similar at first glance to constructions with pronoun and proper name objects, raising the possibility that these objects are incorporated as well. However, I follow Alderete (1998) and Aranovich (2013) in assuming that incorporated nouns undergo movement into the verb (33), as in Baker (1988), while pronouns and proper names do not.

Noun incorporation in Fijian:

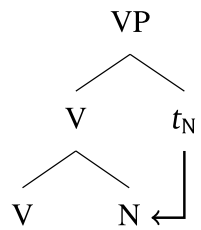

A first superficial difference between incorporated objects and pronoun/proper name objects is that transitive verbs lose their transitive suffix when the noun in- 
corporates $(33 a-b) .{ }^{12}$ Morphologically then, incorporated nouns affect the verb in a different way. More importantly, however, we can show that incorporated nouns occupy a different position than pronouns and proper names. In causative and applicative constructions, as pointed out by Aranovich (2013), incorporated nouns end up inside the verbal complex.

I illustrate with the causative. The causative prefix vaka-/vaa-can combine either with an intransitive or a transitive with an incorporated noun to form a complex verb. In this case, noun incorporation co-occurs with a transitive suffix. Importantly, the incorporated noun must appear before the suffix (34a-b), inside of the verbal complex. $^{13}$

Noun incorporation places noun before transitive suffix:

a. au a vaa-kana-ika-taki Jone.

1SG PST CAUS-eat-fish-TR.PR Jone

'I made Jone eat fish.'

b. e a vaka-gunu-yaqona-taki Jone ko Mere.

3SG PST CAUS-drink-kava-TR.PR Jone ART.PR Mere

'Mere made Jone drink kava.'

These facts show that incorporated nouns are part of the verbal complex and can be accounted for straightforwardly under the head movement analysis in (35). The incorporated noun moves into $\mathrm{V}$, forming a complex head that moves to $v$, as schematized in (35). As a result of successive movement, the incorporated noun appears before

${ }^{12}$ The intransitive form of most verbs is also bare, so that we could think of this as detransitivization. However, there is a small set of verbs whose intransitive form is marked by a prefix, such as voro ('break') (ia). These verbs must still be bare under noun incorporation (ib).

(i)

Incorporated nouns trigger omission of intransitive prefix:
a. e na *(ka)-voro na yalo.
3SG FUT INTR-break ART.N soul
'Hearts will break.'
b. e dau (*ka)-voro yalo ko Eroni. 3SG HAB INTR-break soul ART.PR Eroni 'Eroni breaks hearts.'

${ }^{13}$ The head movement analysis presented here must be complicated somewhat, because incorporated nouns can be modified by adjectives (although not by demonstratives or possessors), even when they appear inside the verbal complex, as in examples like (i).

(i) Incorporated nouns can be modified by adjectives:

e a vaka-gunu-yaqona-yauta-taki Jone ko Mere.

3SG PST CAUS-drink-kava-damp-TR.PR Jone ART.PR Mere

'Mere made Jone drink damp kava.'

Such facts suggest that noun incorporation does not involve head movement, but phrasal movement of a larger constituent. See Barrie and Mathieu (2016) for similar patterns in a range of noun incorporation languages. 
the transitive suffix. ${ }^{14}$ (I assume all of these movements occur within the phrase that undergoes fronting, so that it is a constituent larger than VP that moves.)

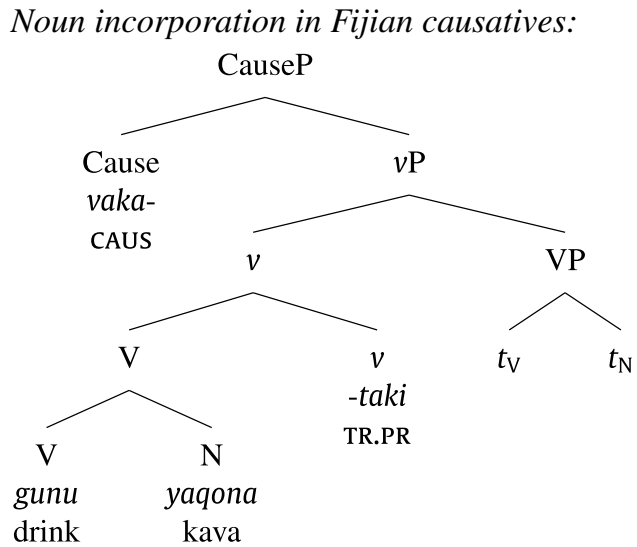

This construction also allows us to distinguish noun incorporation from the adjacency effect found with pronoun/proper name objects. Unlike incorporated nouns, pronouns and proper names can never appear inside the verbal complex, in between the verb and the transitive suffix (36a-b).

Pronoun/proper name objects cannot appear in verbal complex:

a. *au a va-kana-koya-taki Jone.

1SG PST CAUS-eat-3SG-TR.PR Jone

'I made Jone eat it/him/her.'

b. *e a vaka-gunu-Jone-taka na yaqona ko Mere.

3SG PST CAUS-drink-Jone-TR.N ART.N kava ART.PR Mere

'Mary made John drink kava.'

Instead, as we expect from material that is not incorporated, pronoun and proper name objects follow the entire verb, including the transitive suffix, as in examples like (37a-b).

Pronoun/proper name objects follow entire causative verb:

a. e a va-kan-i Jone ko Mere va na niu.

3SG PST CAUS-eat-TR.PR Jone ART.PR Mere P ART.N coconut

'Mere made Jone eat coconut.'

b. au a va-kana-ika-taki Jone.

1SG PST CAUS-eat-fish-TR.PR Jone

'I made Jone eat fish.'

\footnotetext{
${ }^{14}$ For ease of exposition, I have opted for a somewhat simplified structure. The causative construction more likely has a more articulated structure with an additional $v \mathrm{P}$ layer associated with the causative morpheme. The presence of two $v$ layers could provide an explanation for why the transitive suffix is not suppressed in this case. In addition, the transitive suffix used in the causative is the long form, -Caki, which commonly signals applicative structure in Fijian and so might be associated with a more complex verbal structure. None of this affects the argumentation around the status of noun incorporation.
} 
As Aranovich points out, these patterns provide clear evidence that noun incorporation in Fijian reflects a distinct process from the DOM pattern under consideration. In particular, it seems to show that bare nouns undergo movement into the verbal complex, while pronouns and proper names remain in an argument position, presumably the complement position of $\mathrm{V}$. After head movement of $\mathrm{V}$ into $v$, a pronoun/proper name object will remain outside the verbal complex.

For present purposes, nothing hinges on whether noun incorporation is thought of as syntactic or as a lexical process. But there are a few arguments for thinking of noun incorporation in Fijian as a syntactic process. Many examples of noun incorporation make use of a prototypical object (38a), but we can also find examples that clearly do not denote prototypical events (38b). ${ }^{15}$

Noun incorporation does not have to be prototypical:
a. e a gunu yaqona ko Eroni.
3SG PST drink kava ART.PR Eroni
'Eroni drank kava.'
2SG PST eat what
'What did you eat?'
b. iko a kana cava?

In addition to this, incorporated nouns remain referential. As we see in (39), an incorporated noun can be referred to with a pronoun (in this case, an object pronoun that is a part of the $-C a$ suffix, see below).

\section{Incorporated nouns remain referential:}

au a tali iri kau a qai vaka-caca-na $\mathbf{i}_{\mathbf{i}}$ tale.

1SG PST make fan then.1SG PST GAI CAUS-destroy-TR.N again

'I made fans and then I destroyed them.'

I conclude that pronoun/proper name objects do not incorporate into the verb, so that the DOM pattern requires an independent explanation, following Alderete (1998) and Aranovich (2013). In what follows, I provide evidence that pronouns/proper names are subject to an adjacency requirement, because they can appear without an article also when adjacent to a higher verb, across a clause boundary. This construction too will distinguish the marking of pronoun/proper name objects from noun incorporation, which is impossible in this context.

\section{Adjacency across a clause boundary}

In this section, I argue that Fijian pronoun and proper name objects are subject to an adjacency requirement, which I propose in Sect. 5 reflects the application of morphological merger at PF. The main argument for this adjacency requirement comes

\footnotetext{
${ }^{15}$ Noun incorporation is particularly productive with the verbs gunu ('drink') and kana ('eat'), as Dixon (1988) notes. Most other verbs put restrictions on which common nouns may incorporate. The fact that such restrictions are never found with pronoun and proper name objects is another reason to think they do not undergo incorporation.
} 
from the observation that pronouns and proper names can be marked like objects of a higher verb across a clause boundary. In particular, I show that a clefted pronoun/proper name inside an embedded clause can be marked as an object of a higher verb, with article omission and the pronoun/proper name suffix $-\mathrm{Ci}$ on the verb. This effect is reminiscent of raising-to-object or long-distance agreement out of a finite CP (e.g. Polinsky and Potsdam 2001; Branigan and MacKenzie 2002; Deal 2016; Zyman 2018), but I will show that it is uniquely sensitive to adjacency. The object marking pattern is only possible if nothing linearly intervenes between the verb and the pronoun/proper name in the embedded clause. No adverb, postverbal particles, or other argument may intervene between the verb and pronoun/proper name.

\subsection{CP complements and fronting}

The effect we will be concerned with emerges with verbs that embed CP complements, like папи ('think/remember') and kila ('know'), when fronting occurs inside of such embedded clauses. I will first discuss the properties of CP complements and the properties of fronting in Fijian, which I argue, following Potsdam (2009), is the result of clefting.

$\mathrm{CP}$ complements obligatorily occur in VSO order, as the examples in (40a-b) demonstrate.

CP complements appear in VSO order:
a. e kila-a ko Eroni [CP ko cei iko a rai-ca]. 3SG know-TR.N ART.PR Eroni ART.PR who 2SG PST see-TR.N 'Eroni knows who you saw.'
b. *e kila-a [CP ko cei iko a rai-ca] ko Eroni. 3SG know-TR.N ART.PR who 2SG PST see-TR.N ART.PR Eroni 'Eroni knows who you saw.'

Like nominal objects, $\mathrm{CP}$ objects occur with the transitive suffix. Complement clauses pattern with common nouns in that the transitive suffix they appear with is $-\mathrm{Ca}$, whether the CP object is interrogative or declarative (41a-c).

Transitive verbs that embed a CP occur with -Ca:
a. au a nanu-ma [CP ni a rai-ca ko Eroni].
1SG PST remember-TR.N C PST see-TR.N ART.PR Eroni
'I remember that Eroni saw it.'
b. au kila-a [CP ni vuku ko Eroni].
1SG know-TR.N C smart ART.PR Eroni
'I know that Eroni is smart.'
c. au kila-a [cP ko cei iko a rai-ca].
1SG know-TR.N ART.PR who 2SG PST see-TR.N
'I know who you saw.'

Word order inside these complement clauses is the same as in matrix clauses. The usual word order is predicate-initial, as in the examples in (41a-b). In addition, as noted by Dixon (1988), most embedded clauses allow fronting within them, an option available in matrix clauses as well. In an embedded $w h$-question, for example, 
the $w h$-phrase commonly appears fronted (42a-b). Fronting of a non-wh-element is also permitted (42c).

Fronting inside an embedded clause:

a. au nanu-ma [CP na cava iko a tuku-na].

1SG remember-TR.N ART.N what 2SG PST say-TR.N

'I remember what you said.'

b. au kila-a [CP ko cei iko a rai-ca].

1SG know-TR.N ART.PR who 2SG PST see-TR.N

'I know who you saw.'

c. au kila-a [CP ni na ka ya iko a tuku-na].

1SG know-TR.N C ART.N thing that 2SG PST say-TR.N

'I know that you said that thing.'

As $(42 \mathrm{a}-\mathrm{c})$ show, an interesting property of these structures is that fronted nominals surface with their article. Even the wh-pronoun cei ('who') in (42b) appears with the article $k o$, despite the fact that it is an object. ${ }^{16}$ This is at first glance surprising from the perspective of the DOM pattern. However, as Potsdam (2009) shows, fronting in Fijian involves a biclausal cleft structure, so that the initial phrases in $(42 \mathrm{a}-\mathrm{c})$ are in fact predicates.

To see that fronting involves a cleft structure, note first of all that Fijian is a predicate-initial language with no overt copula. The examples in (43a-b) demonstrate.

Fijian is predicate-initial with no copula:

a. e qasenivoli na marama ya.

3SG teacher ART.N woman that

'That woman is a teacher.'

b. e vulavula na vale.

3SG white ART.N house

'The house is white.'

In addition, Fijian permits both $w h$ - in situ as well as fronting of $w h$-phrases, as shown in $(44 a-b)$.

(44) Fijian allows wh- in situ:

a. e a rai-ci cei ko Eroni?

3SG PST see-TR.PR who ART.PR Eroni

'Who did Eroni see?'

b. e a rai-ca na cava ko Eroni?

3SG PST see-TR.N ART.N what ART.PR Eroni

'What did Eroni see?'

As Potsdam points out, these properties mean that fronting structures may underlyingly be clefts. In this analysis, the dislocated phrase is an initial predicate followed by a headless relative (see also Potsdam and Polinsky 2011). The underlying structure

${ }^{16}$ In addition, the embedded verb shows the wrong transitive suffix, $-\mathrm{Ca}$. 
of an example like (45a) is then (45b). The wh-phrase is the predicate of the clause and combines with a headless relative clause, formed by operator movement (45b). ${ }^{17}$

Cleft analysis of fronting:
a. o cei e a rai-ca ko Eroni?
ART.PR who 3SG PST see-TR.N/TR.PR ART.PR Eroni 'Who did Eroni see?'
b. [PredP O cei] [ $\mathrm{CP}_{\mathrm{CP}} \mathrm{Op}$ a rai-ca ko Eroni]? ART.PR who 3SG PST see-TR.N ART.PR Eroni

As evidence for a cleft analysis, Potsdam (2009) points out that fronted phrases behave syntactically like predicates. Recall that Fijian has a set of postverbal particles that contribute adverbial information about the predicate. Like other predicates, fronted wh-phrases may be modified by such particles. An example of a postverbal particle that can appear in wh-questions is dina ('really') (46a). Dina must be postverbal and cannot surface initially (46b). (All of the examples in this discussion are based on Potsdam's (2009:672-675), but in Standard Fijian.)

\section{Dina is a postverbal particle:}

a. e a regu-ca dina na koli ko Pita. 3SG PST kiss-TR.N really ART.N dog ART.PR Peter 'Peter really kissed the dog.'

b. *dina e a regu-ca na koli ko Pita. really 3SG PST kiss-TR.N ART.N dog ART.PR Peter 'Peter really kissed the dog.'

When a wh-phrase is fronted, however, dina can appear after the verb (47a), just as in other environments, but also after the fronted $w h$-phrase $(47 \mathrm{~b})$.

A postverbal particle can modify a fronted wh-phrase:

a. ko cei e a regu-ca dina na koli?

ART.PR who 3SG PST kiss-TR.N really ART.N dog 'Who really kissed the dog?'

b. ko cei dina e a regu-ca na koli? ART.PR who really 3 SG PST kiss-TR.N ART.N dog 'Who really kissed the dog?'

The facts in (47a-b) make sense if the fronted $w h$-phrase is a predicate, which may also be associated with its own postverbal particles. ${ }^{18}$ In contrast, examples like (47b)

\footnotetext{
${ }^{17}$ As Potsdam (2009) notes, evidence for such a movement step comes from the fact that fronting is islandsensitive, displays Strong Crossover, and reconstruction for Principle C.

${ }^{18}$ The initial predicate of a cleft retains the article and patterns in this respect with other non-predicational copular clauses, like specificational or equative clauses (ia-b).
}

(i) Non-predicational copular clauses retain articles:
a. o au ko Eroni.
DET.PR 1SG DET.PR Eroni
'I am Eroni.' 
are hard to account for under a $w h$-movement analysis. Particles like dina otherwise occur only in post-predicate position. In addition, note that a postverbal particle like dina cannot be analyzed as directly modifying the $w h$-phrase, since in situ $w h$-phrases cannot be followed by it (48a-b).

Dina is not licensed by an in situ wh-phrase:
a. e a regu-ca dina na koli ko cei?
3SG PST kiss-TR.N really ART.N dog ART.PR who
'Who really kissed the dog?'
b. *e a regu-ca na koli ko cei dina?
3SG PST kiss-TR.N ART.N dog ART.PR who really
'Who really kissed the dog?'

Fronted phrases that are not $w h$ - in nature also act as predicates in this respect, as the examples in (49a-b) attest.

\section{Dina as a postverbal particle after a fronted proper name:}

a. ko Pita e a regu-ca dina na koli.

ART.PR Pita 3SG PST kiss-TR.N really ART.N dog

'Pita really kissed the dog.'

b. ko Pita dina e a regu-ca na koli.

ART.PR Pita really 3 SG PST kiss-TR.N ART.N dog

'Pita really kissed the dog.'

Other postverbal particles, such as tale ('only') and duadua ('alone'), display similar behavior, as Potsdam (2009) discusses. ${ }^{19}$

On the basis of these facts, I propose that fronting in Fijian involves a biclausal cleft structure. This understanding of fronting will be important when we turn to the interaction of clefting in embedded clauses with object marking: a pronoun/proper name that is clefted can be marked as an object of a higher verb. Note also that the cleft analysis provides an explanation of the fact that fronted phrases always appear with articles, even when it is a pronoun or proper name object that has been fronted. ${ }^{20}$

\subsection{Object marking across a clause boundary}

This section demonstrates that pronouns and proper names can be marked as an object of a higher verb across a CP boundary, as long as the verb is surface-adjacent. As in a

\footnotetext{
b. na gonevuli koya o au.

DET.N student that DET.PR $1 \mathrm{SG}$

'That student is me.'
}

In predicational copular sentences, though, common nouns do lose their article, as in (43a), and appear with verbal morphology, like the subject clitic $e$.

${ }^{19}$ Note that fronted phrases do not seem to be able to combine with preverbal particles encoding tense and aspect. The same is true of other nominal predicates in Fijian in which the article is retained. Preverbal particles seem to be available only with nominal predicates that lose the article, as in (43a).

${ }^{20}$ That the verb appears with the $-\mathrm{Ca}$ suffix regardless of clefted constituent still requires explanation. I posit that $-\mathrm{Ca}$ reflects the status of the null operator that moves into the left periphery of the lower clause, which, like cava ('what'), is treated as part of the class of common nouns. 
simplex clause, the article ko/o is omitted and the verb surfaces with - $C i$. This effect does not reflect raising-to-object or long-distance agreement, but is sensitive to linear adjacency. Any type of overt element that intervenes between the higher verb and pronoun/proper name, whether associated with the lower or higher clause, disrupts object marking. On this basis, I argue that pronouns and proper names in Fijian are subject to an adjacency requirement. ${ }^{21}$

As discussed in the previous section, Fijian embedded clauses allow fronting, by means of a cleft structure. One of the consequences of clefting is that the clefted phrase can end up immediately adjacent to the embedding verb. In this configuration, Fijian allows object marking across a finite clause boundary. A clefted pronoun or proper name in an embedded clause can be treated morphologically as an object of the higher verb. For example, an embedded wh-cleft with the wh-pronoun cei ('who') like (50a) can also be realized as (50b), with omission of the article ko/o and the $-\mathrm{Ci}$ suffix on the higher verb. ${ }^{22}$ A similar option is available with a left-dislocated proper name, as in (50c).

Article ko/o omitted with -Ci on embedding verb:

a. au kila-a [CP ko cei iko a rai-ca]. 1SG know-TR.N ART.PR who 2SG PST see-TR.N 'I know who you saw.'

b. au kila-i [CP cei e a rai-ca na cava]. 1SG know-TR.PR who 3SG PST see-TR.N ART.N what 'I know who saw what.'

c. au kila-i [CP Eroni e na sure-ti Jone]. 1SG know-TR.PR Eroni 3SG FUT invite-TR.PR Jone 'I know Eroni will invite Jone.'

As with regular pronoun/proper name objects, article omission is impossible when the verb carries the $-C a$ suffix $(51 a-b)$.

\footnotetext{
${ }^{21}$ This construction is distinct from the constructions discussed by Massam (1985), which she calls ECM, in which an argument from the lower clause appears in object position in the higher clause (i), with the verb vinaka ('want').
}

(i)

"ECM" construction with vinaka:
e vinaka-ti ira na turaga [CP me ra vaqara-i iko].
3SG want-TR.PR 3PL ART.N man C C 3PL look.for-TR.PR 2SG
"Someone wants the men to look for you.'

These constructions are different from the ones discussed here in a number of ways. The object is unambiguously in the higher clause and can precede the subject or a complementizer. In addition, the object is doubled by a pronominal form in the lower clause, like the subject clitic in (i). Finally, this construction is impossible with wh-phrases, presumably because these cannot be interpreted in the higher clause. As a result, these may be more plausibly analyzed as proleptic constructions. To control for the availability of this construction, I use examples with wh-phrases for the crucial cases.

${ }^{22}$ Note that this construction does not involve a free relative, because it is available in a multiple $w h$ question, as in (50b). My thanks to Masha Polinsky (p.c.) for discussion of this point. 
Article ko/o cannot be omitted with -Ca on embedding verb:
a. au kila-a $\quad[\mathrm{CP} *(\mathbf{k o})$ cei iko na sure-ta].
1SG know-TR.PR ART.PR who 2SG FUT invite-TR.N 'I know who you will invite.'
b. au a nanu-ma [CP $*(k)$ cei iko a rai-ca]. 1SG PST remember-TR.PR ART.PR who 2SG PST see-TR.N 'I remembered who you saw.'

Similarly, the $-C i$ suffix is only possible if the article is omitted (52a-b).

Article must be omitted if -Ci suffix is used:
a. au kila-i $\quad$ [CP (*ko) cei iko a rai-ca].
1SG know-TR.PR ART.PR who 2SG PST see-TR.N
'I know who you saw.'
b. au nanu-mi [CP $\left({ }^{*} \mathbf{k o}\right)$ cei iko a sure-ta].
1SG remember-TR.PR ART.PR who 2SG PST invite-TR.N
'I remember who you invited.'

It is difficult to determine whether common nouns participate in this as well, because object marking with these is only visible in the - Ca suffix. As noted above, the - Ca suffix surfaces anyway with embedded CP objects. We can show, however, that noun incorporation is not possible in this derived environment. The verb kila ('know') allows noun incorporation with the object $k a$ ('thing') (53a). Noun incorporation is impossible across a clause boundary (53b).

No noun incorporation after fronting:
a. au kila ka.
1SG know thing
'I know things.'
b. *au kila [CP ka iko a tuku-na]. 1SG know thing 2SG PST say-TR.N 'I know you said things.'

This effect is another way in which noun incorporation can be distinguished from the adjacency requirement of pronouns and proper names (see also Sect. 3.3), showing that pronouns and proper names do not undergo incorporation into the verb.

That object marking is possible in this environment is surprising, both because the embedded clause is finite, but also because it shows that the DOM pattern persists in a derived environment. I will argue that object marking is possible because pronouns and proper names can be licensed through an operation of morphological merger with a verb at PF. Although a clefted pronoun or proper name resides in a different clause, it can still be linearly adjacent with the embedding verb. As a result, an operation of morphological merger can apply.

At first glance, the construction described above is reminiscent of long-distance agreement into embedded clauses, as in languages like Tsez and Innu-aimûn (Polinsky and Potsdam 2001; Branigan and MacKenzie 2002), or raising-to-object out of finite CPs (e.g. Deal 2016; Zyman 2018). However, unlike long-distance agreement or object raising, article omission in Fijian is only possible with surface adjacency. 
A pronoun or proper name in the embedded clause can only be treated as an object of the higher verb if no overt material intervenes. No object agreement or object raising is involved. Article omission is licensed strictly through adjacency at PF, which I will argue reflects the application of morphological merger.

We can see the effects of surface adjacency in a number of ways. Let me first show that the nominal must be initial in the embedded clause. Article omission is only possible if the pronoun or proper name is clefted (54).

Article omission is impossible without clefting:

*au kila-i [CP ni e na sure-ti Jone Eroni].

1SG know-TR.PR C 3SG FUT invite-TR.PR Jone Eroni

'I know Eroni will invite Jone.'

Complementizers also disrupt the effect. In an embedded declarative, the complementizer $n i$ is optional after a verb like kila ('know'). Article omission is only possible when the complementizer is omitted $(55 \mathrm{a}-\mathrm{c})$.

Article omission is impossible after complementizer:
a. au kila-i
[CP Eroni
na sure-ti
Jone].
1SG know-TR.PR Eroni 3SG FUT invite-TR.PR Jone
'I know Eroni will invite Jone.'
b. *au kila-i [CP ni Eroni e na sure-ti Jone].
1SG know-TR.PR C Eroni 3SG FUT invite-TR.PR Jone
'I know Eroni will invite Jone.'
c. au kila-a [CP ni ko Eroni e a rai-ci iko].
1SG know-TR.N C DET.PR Eroni 3SG PST see-TR.PR 2SG
'I know Eroni saw you.'

So far, these facts are consistent with treating this phenomenon as a long-distance agreement effect. Such agreement typically requires the target of agreement to be at the edge of the embedded clause (see Polinsky and Potsdam 2001 and Branigan and MacKenzie 2002, for instance). However, in Fijian, article omission places restrictions on the higher clause as well. Because this object marking is only possible with strict adjacency, no overt material can intervene between verb and pronoun/proper name in the higher clause either. For example, since CP objects occur in VSO order, article omission is disrupted when the higher verb has an overt subject, which must appear in between the verb and embedded clause (56a-b). This can only be fixed by fronting the overt subject (56c).

\section{Overt subject in VSO disrupts article omission:}

a. e kila-a ko Eroni [CP ko cei iko a rai-ca]. 3SG know-TR.N ART.PR Eroni ART.PR who 2SG PST see-TR.N 'Eroni knows who you saw.'

b. *e kila-i kn Eroni [cP cei iko a rai-ca]. 3SG know-TR.PR ART.PR Eroni who 2SG PST see-TR.PR 'Eroni knows who you saw.'

c. ko Eroni e kila-i [CP cei iko rai-ca]. ART.PR Eroni 3SG know-TR.PR who 2SG see-TR.PR 'It is Eroni who knows who you see.' 
Other overt material has the same effect. For example, if a postverbal particle surfaces after the embedding verb, o/ko can no longer be omitted $(57 \mathrm{a}-\mathrm{b})$.

\section{Postverbal particle after higher verb disrupts article omission:}

a. au kila-a tu ga [CP ko cei iko na sureta].

1SG know-TR.N always ART.PR who 2SG FUT invite

'I always know who you will invite.'

b. *au kila-i tu ga [CP cei iko na sureta].

1SG know-TR.PR always who 2SG FUT invite

'I always know who you will invite.'

The same effect is found with higher adverbs, like nanoa ('yesterday'). Article omission is impossible if nanoa intervenes between the verb and complement clause $(58 \mathrm{a}-\mathrm{b})$, and is only licit if the adverb follows the complement clause $(58 \mathrm{c})$.

Adverb after higher verb disrupts article omission:

a. au a gai kila-a nanoa [CP ko cei e talei-taka

1SG PST GAI know-TR.N yesterday ART.PR who 3SG like-TR.N

ko Eroni].

ART.PR Eroni

'I found out yesterday who Eroni likes.'

b. *au a gai kila-i nanoa [CP cei e talei-taka ko

1SG PST GAI know-TR.PR yesterday who 3SG like-TR.PR ART.PR

Eroni].

Eroni

'I found out yesterday who Eroni likes.'

c. au a gai kila-i [

1SG PST GAI know-TR.PR who 3SG like-TR.N ART.PR Eroni

nanoa.

yesterday

'I found out yesterday who Eroni likes.'

We can also use overt material in the higher clause to rule out an analysis that posits that the pronoun/proper name is in the higher clause, either because it is a proleptic object or because it undergoes object raising or scrambling. As the examples in $(59 \mathrm{a}-\mathrm{c})$ attest, the pronoun/proper name cannot appear before material in the higher clause, such as a subject (59a), postverbal particle (59b), or adverb (59c).

Pronoun/proper name cannot appear in higher clause:

a. *e kila-i cei ko Eroni [CP iko a rai-ca]. 3SG know-TR.PR who ART.PR Eroni 2SG PST see-TR.PR 'Eroni knows who you saw.'

b. *au kila-i cei tu ga [CP iko na sureta].

1SG know-TR.PR who always 2SG FUT invite 'I know who you will invite.' 


\section{c. *au a gai kila-i cei nanoa [ ${ }_{\mathrm{CP}}$ e talei-taka ko 1SG PST GAI know-TR.N who yesterday 3SG like-TR.N ART.PR Eroni]. \\ Eroni \\ 'I found out yesterday who Eroni likes.'}

The clefted wh-phrase then remains in the lower clause and does not scramble into the higher clause, since any such operation should permit it to precede some matrix clause material. In addition, wh-phrases presumably must remain in the lower clause for interpretation. ${ }^{23}$

We can rule out even the idea of string-vacuous object movement by putting a whphrase in a disjunctive structure. ${ }^{24}$ Fijian permits a disjunction of $w h$-phrases as the predicate of a $w h$-cleft $(60 \mathrm{a}-\mathrm{b})$.

Disjunction of wh-phrases can be predicate of wh-cleft:

a. [orp ko cei se na cava] iko a rai-ca?

ART.PR who or ART.N what 2SG PST see-TR.N

'Who or what did you see?'

b. au kila-a [CP [OrP ko cei se na cava] iko a

1SG know-TR.N ART.PR who or ART.N what 2SG PAST

rai-ca].

see-TR.N

'I know who or what you saw.'

A pronoun/proper name in such a disjunctive structure can license article omission, but only if it is the first disjunct and the conditions on surface adjacency are met. If headed by $\mathrm{ko} / \mathrm{o}$, the first disjunct can trigger - $\mathrm{Ci}$ marking on the higher verb (61a), but not the second (61b):

Article omission is possible if pronoun/proper name is first disjunct:
a. au kila-i [CP [orp cei se na cava] iko a rai-ca]. 1SG know-TR.PR who or ART.N what 2SG PAST see-TR.N 'I know who or what you saw.'
b. *au kila-i [CP [orp na cava se cei] iko a rai-ca]. 1SG know-TR.PR ART.N what or who 2SG PAST see-TR.N 'I know who or what you saw.'

It is clear from such examples that the $w h$-phrase has not undergone any movement, because this would violate the Coordinate Structure Constraint. In addition, the ordering effect is another piece of evidence that only surface adjacency matters.

The facts presented in this section make clear then that the Fijian DOM pattern is about linear adjacency. On the basis of this, I argue that adjacency can allow a nominal to escape the need to undergo Case licensing (Levin 2015; Branan 2017), through the application of a morphological merger operation at PF. In contrast, subjects uni-

\footnotetext{
${ }^{23}$ These facts also let us rule out a prolepsis analysis.

${ }^{24}$ Fijian coordination seems to involve a comitative structure, so does not provide a good test for the Coordinate Structure Constraint.
} 
formly receive nominative case, and so do not show a differential marking pattern. I develop this proposal in detail in the next section.

\section{The role of adjacency in Case licensing}

DOM patterns crosslinguistically involve additional case morphology on objects higher on an animacy or definiteness hierarchy. I take the presence of an adjacency requirement to show that Fijian is no different: additional Case licensing is necessary for such objects. What is different about Fijian is that this licensing need can be avoided through morphological merger. In this section, I first argue that the adjacency effect reflects the application of morphological merger of the pronoun/proper name with a verb at PF (Levin 2015; Branan 2017; cf. Ackema and Neeleman 2003), specifically through Embick and Noyer's (2001) Local Dislocation. I suggest that morphological merger is necessary because Fijian lacks accusative case assignment. I then argue that common nouns are structurally reduced, based on the fact that they lack number and definiteness. As a result, common nouns lack the requisite structure for a $[u$ Case $]$ feature and vacuously satisfy the Case Filter.

\subsection{Morphological merger of pronouns and proper names}

In this section, I develop an account of the Fijian DOM pattern, repeated in (62a-b), based on the idea that the application of morphological merger can allow a nominal to avoid the Case Filter, resulting in an apparent adjacency requirement. This approach will also explain the possibility of object marking across a clause boundary discussed in the previous section.

Two types of objects in Fijian:

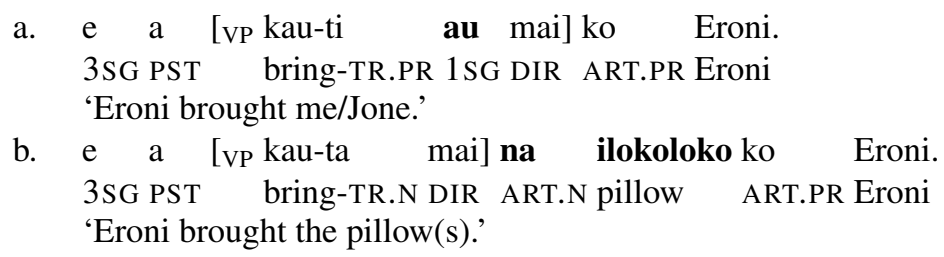

As a point of departure, I take the position of the pronoun object in (62a) and the common noun object in (62b) to both reflect object positions of Fijian, in principle available to all objects. In other words, any object should be able to remain inside the fronted VP or move out before VP-fronting applies. However, I propose that Fijian lacks a mechanism for assigning accusative case to objects in the syntax. It does not matter for present purposes what theory of case this is stated in. We could interpret the absence of accusative case either as an inability of $v$ to assign Case, in a Chomskian view of Case (Chomsky 1981 et seq.) or as the absence of a dependent case rule in the sense of Marantz (1991). In any case, I suggest that, regardless of which of the two positions in (62a-b) an object occupies, Fijian objects are never Case-licensed 
in narrow syntax. Objects will contrast in this respect with subjects, which I propose always receive nominative from $\mathrm{T}$, so that no differential subject marking pattern arises.

At the same time, I adopt the Case Filter, so that all nominals require Case licensing (Vergnaud 2008/1977). A consequence of the absence of accusative case is that objects will not be able to surface without violating the Case Filter, unless an alternative licensing strategy is able to apply. I propose that, in order to be licensed, pronouns and proper names undergo morphological merger with a verb at PF, through the application of Local Dislocation (Embick and Noyer 2001). The application of Local Dislocation is what results in an apparent adjacency requirement. In contrast, I will argue that common nouns are always structurally reduced, lacking the requisite structure to introduce a Case feature, and so vacuously satisfy the Case Filter.

Morphological merger allows a nominal to escape the Case Filter in the following way (see also Baker 1988 and Levin 2015). I propose that Fijian pronouns and proper names have a full KP structure, in which the article ko/o is the realization of the $\mathrm{K}$ (ase) head (see also Ott 2008). As a result, the article $k o / o$ contributes the [ $u$ Case] feature that needs to be licensed in the syntax. This view is represented in $(63) .^{25}$

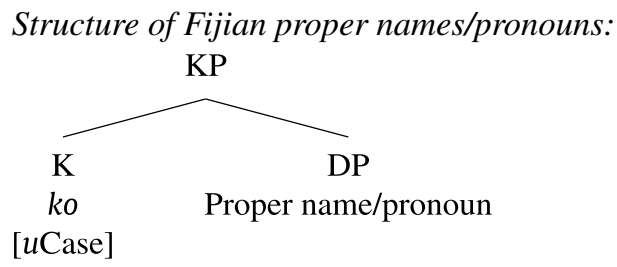

The article ko/o spells out with subjects, because these receive nominative case from T. But, with objects, the article introduces a Case feature that cannot be licensed. This situation can be resolved through morphological merger of the pronoun/proper name with the verb. In particular, I propose that it is possible for a pronoun/proper name to be Merged without an article, thus avoiding the Case licensing issue, as long as the pronoun/proper name undergoes morphological merger with a verb, and so becomes part of a different extended projection.

To see how this approach works, consider the structure of an example like (64a), a pronoun/proper name object before a postverbal particle. Both the postverbal particle and the object are inside the fronted VP, and the pronoun/proper name is verbadjacent (64b). Occupying this object position enables the pronoun/proper name to undergo Local Dislocation under adjacency with the verb at PF (64c). (The verb has moved up to $v$ to combine with the transitive suffix.)

\footnotetext{
${ }^{25}$ In this view, ko/o is the default realization of $\mathrm{K}$ with proper names/pronouns, absent only when the nominal undergoes morphological merger with an immediately preceding verb/preposition. It is also in principle consistent with my approach to treat $\mathrm{K}$ as the realization of nominative only, so that the proposal about extended projections below would not be necessary. Note that Local Dislocation is still necessary, to capture the adjacency requirement on pronouns/proper names.
} 
Proper name/pronoun objects undergo morphological merger:

a. e a [vp kau-ti Jone mai] ko Eroni. 3SG PST bring-TR.PR Jone DIR ART.PR Eroni 'Eroni brought Jone.'

b.

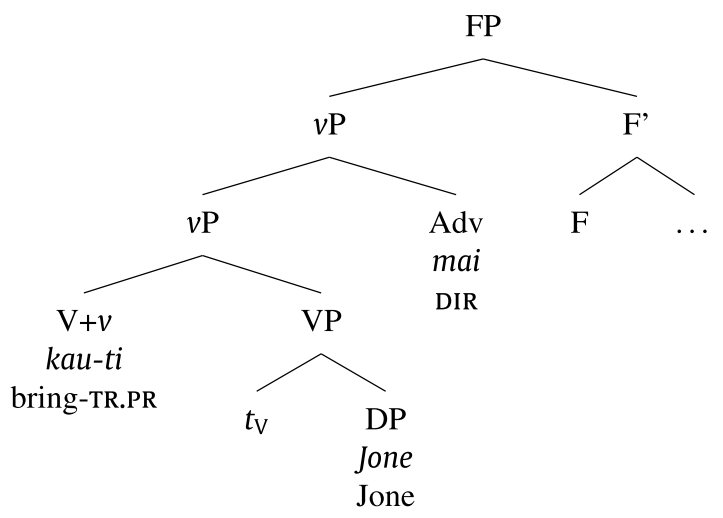

c. $\quad\left[{ }_{v \mathrm{P}} \mathrm{V}+v[\right.$ Jone $\left.]\right] \rightarrow\left[{ }_{v \mathrm{P}} \mathrm{V}+v+\right.$ Jone [Jone $\left.]\right]$

Local Dislocation is a rebracketing operation that means that the pronoun/proper name is now part of a complex head with the verb and its affixes. As a result, it is part of the extended projection associated with the verb. Because of the absence of the $\mathrm{K}$ head, the article $k o / o$ is not realized and the object does not violate the Case Filter.

It is important in this approach that there is a requirement that extended projections must generally be complete, so that $\mathrm{K}$ cannot freely be omitted (see also Levin 2015, Sheehan and Van der Wal 2016). In this view, there are two ways in which a pronoun/proper name can be part of a complete extended projection in Fijian. Either the article ko/o is projected, introducing a Case licensing need, or Local Dislocation allows the pronoun/proper name to be part of the extended projection of the verb. See also Baker (1988) and Levin (2015: Sect. 4.3) for similar proposals for how (pseudo-)noun incorporation allows a nominal to escape Case licensing requirements.

In support of the application of Local Dislocation, we find prosodic evidence for the idea that the pronoun/proper name forms a tighter morphophonological unit with the verb than other elements. Scott (1948:748), in his description of Fijian intonation, observes that object pronouns are treated as part of the same prosodic phrase as the verb. In contrast, common noun objects are set off in their own prosodic phrase. The same conclusion is evident in Schütz's (2014) description of Fijian prosody (402). ${ }^{26}$

\footnotetext{
${ }^{26}$ There may be some morphophonological evidence for word formation as well. As Schütz (2014) points out, adjacent vowels can form diphthongs across morpheme boundaries word-internally. The final $i$ of the transitive suffix can optionally form a diphthong with a suitable initial vowel of the following proper name, such as $i u$ (ia). Similarly, when the pronoun/proper name starts with $i$ as well, the two adjacent vowels can be pronounced as a long vowel (ib).
} 
This view accounts for the observation that pronoun/proper name objects must remain adjacent to the verb and cannot vacate the VP when a postverbal particle is around. An example like (65) is ungrammatical, because the pronoun/proper name is not adjacent to the verb and so could not undergo Local Dislocation.

$$
\begin{aligned}
& \text { *e a [vP kau-ti/ta } \\
& \text { 3SG PST bring-TR.PR/TR.N } \\
& \text { 'Eroni brought me.' }
\end{aligned}
$$

As a result, the only constructions in which a pronoun/proper name could move out of a fronting VP are ones in which there are no postverbal particles, so that the movement ends up being string-vacuous and the verb and object are still adjacent.

In addition to this, an adjacency account provides an explanation of why clefted pronouns and proper names are optionally marked like objects of a higher verb in examples like (66a-b).

Article kolo omitted with -Ci on embedding verb:
a. au kila-i [CP cei e a rai-ca na cava]. 1SG know-TR.PR who 3SG PST see-TR.N ART.N what 'I know who saw what.'
b. au a nanu-mi [CP cei iko a rai-ca]. 1SG PST remember-TR.PR who 2SG PST see-TR.N 'I remembered who you saw.'

Local Dislocation only requires linear adjacency, and so is in principle insensitive to whether the nominal in question originates in the same clause. In examples like $(66 \mathrm{a}-\mathrm{b})$, the pronoun/proper name has an independent Case licensing source in the lower clause, as the predicate in a cleft structure. I propose that this Case licensing source is the Pred head, as in Matushansky (2008a). Pred provides a source of Case in for all predicates in copular clauses, and so in clefts also. However, as long as the environment for morphological merger is met, it is possible for the pronoun/proper name to undergo Local Dislocation with the higher verb (67).

$$
\left[{ }_{v \mathrm{P}} \mathrm{V}+v[\mathrm{CP}[\mathrm{cei}] \ldots]\right] \rightarrow\left[{ }_{\nu \mathrm{P}} \mathrm{V}+v+\mathrm{cei}[\mathrm{CP}[\text { cei }] \ldots]\right]
$$

This view then explains why fronted phrases can optionally be marked as objects of a higher verb, but only if there is surface adjacency. ${ }^{27}$ If any material surfaces in the

(i) Long vowels and diphthongs can form across verb and object:
a. au a rai-ci Ulita.
1SG PST see-TR.PR Ulita
'I saw Ulita.'
b. au a rai-ci iratou.
1SG PST see-TR.PR 3PAUC
'I saw them.'

\footnotetext{
${ }^{27}$ An interesting question is whether the clefted predicate should be accessible for morphophonological operations in the higher clause, in light of contemporary assumptions about cyclicity (e.g. Chomsky 2001). Although a clefted predicate is the initial element in the embedded CP, it is presumably not on the phase edge, and so should perhaps be in an opaque domain for PF operations. There are at least two options for
} 
higher clause, in between the verb and the pronoun/proper name, Local Dislocation is blocked, as examples like (68a-b), repeated from Sect. 4.2, demonstrate.

\section{Overt material in higher clause blocks Local Dislocation:}
a. *e kila-i
ko Eroni [CP cei iko a rai-ca].
3SG know-TR.PR ART.PR Eroni who 2SG PST see-TR.PR
'Eroni knows who you saw.'
b. *au kila-i tu ga [CP cei iko na sureta].
1SG know-TR.PR always who 2SG FUT invite
'I know who you will invite.'

In this way, the idea that pronouns and proper names escape the Case Filter through morphological merger at PF can capture the apparently unusual restrictions on their distribution: that the article is absent and that they must be verb-adjacent. In addition, this view of the Case licensing of pronouns and proper names extends straightforwardly to the phenomenon of object marking across clause boundaries discussed in Sect. 4.2, and its sensitivity to surface adjacency.

\subsection{Common noun objects are caseless}

I focus now on the syntax of common noun objects. Recall that common noun objects must appear with the article $n a$ and obligatorily vacate the VP (69a-b).

\section{Common nouns follow postverbal particles:}

a. e a [vP kau-ta
3SG PST bring-TR.N mai] na ilokoloko ko

In this section, I argue that common noun objects are not subject to the adjacency requirement because they lack a Case feature always. I propose that common nouns are caseless because they are structurally reduced, and so do not require Case licensing to begin with (see Danon 2006 and Ormazabal and Romero 2013 for similar approaches to DOM patterns, among others). As a result, common nouns are able to surface with their article na and do not need to be licensed by Local Dislocation.

There are a number of pieces of evidence to suggest that common nouns are not full DPs. First of all, common nouns in Fijian lack number. As evident in (70a-b), the form of the noun does not change regardless of whether it expresses singular or plural (or paucal and dual).

\footnotetext{
dealing with this issue. One is to simply deny that morphological merger must be sensitive to syntactic cyclicity and allow it to operate purely on the linear string. The second is to posit that Fijian nominal predicates do not project a fully-fledged clause, so that they are not associated with a full syntactic domain. There is some independent evidence that this latter suggestion is on the right track, since nominal predicates that retain the article in general lack preverbal material in Fijian, such as subject clitics and tense/aspect markers.
} 
Common nouns do not show number:

a. e a rai-ca na koli na gone.

3SG PST see-TR.N ART.N dog ART.N child

'The child saw the dog.'

b. era a rai-ci ira na koli na gone.

3PL PST see-TR.PR 3PL ART.N dog ART.N child

'The children saw the dogs.'

In contrast, Fijian pronouns distinguish four numbers: singular, dual, paucal and plural.

Table 1. Fijian independent pronouns.

\begin{tabular}{l|llll}
\hline & SG & DU & PAUC & PL \\
\hline 1EXCL & au & keirau & keitou & keimami \\
1 INCL & - & keidaru & kedatou & keda \\
2 & iko & kemudrau & kemudou & kemuni \\
3 & koya & rau & iratou & ira
\end{tabular}

This follows if common nouns lack a Num(ber) projection that is present in other DPs.

A second argument for the idea that common nouns do not project a full DP is that they do not combine directly with numerals. As discussed by Dixon (1988) and Aranovich (2015), numerals are added to the noun phrase in a relative clause, in which the numeral is the main predicate $(72) .{ }^{28}$

Numerals are introduced through relative clauses:

au vaqa-ra tiko [[CP e dua] na gone].

1SG look.for-TR.N PROG 3SG one ART.N child

'I am looking for a child.'

(lit.) 'I am looking for a child that is one.'

We can explain this if common nouns lack the requisite projection for introducing numerals. $^{29}$

Finally, Fijian does not have definite or indefinite articles. The one candidate for such an element is the article $n a$, which is often used in contexts in which a definite interpretation is most natural, as pointed out by Schütz (2014). The numeral dua ('one') is typically used for singular indefinites instead, regardless of specificity, as in (73a). However, dua, like other numerals, must still appear with na.

Numeral is used for singular indefinites:

a. au vaqa-ra tiko e dua na gone.

1SG look.for-TR.N PROG 3SG one ART.N child

'I am looking for a child (specific/non-specific).'

\footnotetext{
${ }^{28}$ As evident in (72), relative clauses with numerals in them differ from other relative clauses in that they may be preposed before the article na. Aranovich (2015) argues convincingly that such structures are head-internal relative clauses.

${ }^{29}$ An alternative explanation might be that numerals in Fijian must be the main predicate of a clause.
} 

b. au vaqa-ra tiko na gone.
1SG look.for-TR.N PROG ART.N child
'I am looking for the/*a child.'

$\mathrm{Na}$ can also yield a plural definite interpretation (74a). Indefinite objects are usually preferentially expressed with noun incorporation (74b).

\section{Noun incorporation used for plural indefinites:}

a. e a kau-ta mai na ilokoloko ko Eroni. 3SG PST bring-TR.N DIR ART.N pillow ART.PR Eroni 'Eroni brought the pillows.'

b. e a kau ilokoloko ko Eroni. 3SG PST bring pillow ART.PR Eroni 'Eroni brought pillows.'

However, in subject position, where incorporation is not available, na is compatible with indefinite interpretations as well (75).

\section{Article na ambiguous in subject position:}
a. e a luku-ti au na niu. 3SG PST fall-TR.PR 1SG ART.N coconut '(The) coconuts fell on me.'
b. e levu na koli.
3SG many ART.N dog
'There are many dogs.' (lit. 'Dogs are many.')

These facts show that $n a$ is not a genuine definite article. ${ }^{30}$ We can explain this if common nouns do not project a DP layer where definiteness would be encoded. ${ }^{31}$

To capture these facts, I propose that common nouns in Fijian only ever project up until $n \mathrm{P}$, with $n a$ instantiating $n$ (76), and so lack the requisite structure to contain a [uCase] feature.

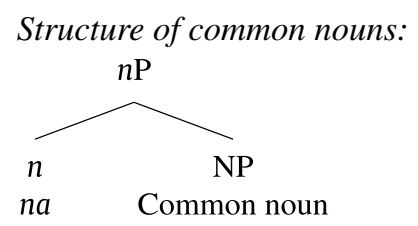

In this view, the articles ko/o and na are not alike and represent different functional heads in the extended nominal projection. Despite their superficial similarities, common nouns and proper names/pronouns project nominals of different sizes. The result is that only pronouns and proper names require Case licensing. ${ }^{32}$ To make sure this structural difference results in an asymmetry between common nouns and proper

\footnotetext{
${ }^{30}$ Another piece of evidence against the idea that $n a$ is a definite article is that it surfaces with wh-phrases like cava ('what').

${ }^{31}$ Note that demonstratives appear after the noun, with adjectives, and can be treated as adjuncts.

${ }^{32}$ See Kalin (2018) for a theory that extends this type of approach across differential object marking patterns. Note that caselessness does not mean that a common noun argument can be added freely to any
} 
names/pronouns, it is important that Local Dislocation cannot apply to common nouns vacuously. For the sake of concreteness, I posit that Local Dislocation is a Last Resort operation, so that it is invoked only where necessary (see also fn. 41).

The asymmetry found with objects is not evident with subjects, since subjects of all types surface in the same positions. I propose that nominative case from $\mathrm{T}$ is always available, unlike accusative case. As a result, pronoun and proper name subjects are licensed without a need for morphological merger. According to the account developed above, common noun subjects should be caseless, like common objects. It is hard to test this prediction directly. Since the ordering of subjects is relatively free (they always occur outside the fronted VP), we cannot detect whether this distinction manifests itself in a positional difference as well. In addition, Fijian does not have true non-finite clauses (e.g. Dixon 1988). With predicates that do trigger subject raising, like the negative verb sega, raising is optional, regardless of whether the subject is a pronoun/proper name or common noun $(77 \mathrm{a}-\mathrm{d}) .{ }^{33}$

Raising is optional with all types of subjects:
a. au sega ni rai-ca e dua na koli.
1SG NEG C see-TR.N 3SG one ART.N dog
'I didn't see a dog.'
b. e sega ni-u rai-ca na koli.
3SG NEG C-1SG see-TR.N ART.N dog
'I didn't see the dog.'
c. na marama e sega ni rai-ca na koli.
ART.N woman 3SG NEG C see-TR.N ART.N dog
'The woman didn't see the dog.'
d. e sega ni rai-ca na marama na koli.
3SG NEG C see-TR.N ART.N woman ART.N dog
'The woman didn't see the dog.'

In the realization of possessive structures, however, there are some patterns that may be interpreted as evidence for the idea that common nouns are caseless. Pronominal possessors surface as suffixes on a possessive classifier (78a), or directly on the noun in cases of inalienable possession (78b).

\section{Pronominal suffixes on inalienable nouns:}
a. na no-dratou vale
ART.N CLS.GEN-3PAUC.POSS house
'their (paucal) house'
b. na yalo-daru
ART.N spirit-1 INCL.DU.POSS
'our (inclusive, dual) spirits'

\footnotetext{
construction. Thematic restrictions presumably prevent a common noun object from being added to an intransitive predicate, for example.

${ }^{33}$ Fijian also has a passive construction, in which pronoun and proper name objects appear with $\mathrm{ko} / \mathrm{o}$. This follows from the idea that Local Dislocation is a Last Resort at PF and so will only be triggered if there is no Case licensing in the syntax. Note that whether common nouns are "promoted" in any way in passives is difficult to ascertain, since there is no dedicated subject position.
} 
In contrast, proper name and common noun possessors are marked by the possessive morpheme -i/ni $(79 \mathrm{a}-\mathrm{c}){ }^{34}$

Lexical possessors of inalienable nouns appear with $-i / n i$ :
a. na vale ne-i Eroni
ART.N house CLS.GEN-I Eroni
'Eroni's house'
b. na yalo-i Eroni
ART.N spirit-I Eroni
'Eroni's spirit'
c. na vale ni koli
ART.N house NI dog
'the dog's house'
d. na yalo ni koli
ART.N spirit NI dog
'the dog's spirit'

In addition to this, Dixon observes that a common noun can double a pronominal possessor, as in examples like (80a-b). But this option is impossible with proper names (80c-d), as discussed by Wang (2018) in a detailed investigation of the Fijian possessive system.

Common nouns can double pronominal possessor:
a. na liga-na na marama
ART.N hand-3SG ART.N woman
'the woman's hand'
b. na no-dratou vale na tamata
ART.N CLS.GEN-3PAUC house ART.N person
'the people (paucal)'s house'
c. *na liga-na o Koini
ART.N hand-3SG ART.PR Koini
'Koini's hand'
d. *na no-na vale ko Jone
ART.N CLS.GEN-3SG house ART.PR Jone
'Jone's house'

(Wang 2018:12)

(Wang 2018:33)

We can attribute this difference in the availability of possessor doubling to the idea that common nouns are caseless. In particular, suppose there is only one source of (genitive) case for possessors, morphologically realized as -i/ni or in the form of the pronominal suffix. A nominal doubling a true possessor cannot receive any Case licensing, since this genitive is assigned to the pronominal possessor. Proper names require Case and so cannot enter into a doubling structure. In contrast, common nouns are caseless and so can always double a true possessor.

A question that remains is why common noun objects must vacate the VP. ${ }^{35}$ Even if common nouns do not need to undergo morphological merger, they should in prin-

\footnotetext{
${ }^{34}$ The clitic $-i$ is used with human nouns, while $n i$ is used only with common nouns.

${ }^{35}$ I discuss the alternation between $-\mathrm{Ci} / \mathrm{Ca}$ in Sect. 6.
} 
ciple be able to remain inside the fronting VP, since they do not need to be licensed. Nothing I have said so far explains why examples such as (81) are impossible.

Common noun object cannot appear inside VP:

* a [vp kau-ta na ilokoloko mai] ko Eroni. 3SG PST bring-TR.N ART.N pillow DIR ART.PR Eroni 'Eroni brought the pillows.'

I suggest that the obligatory evacuation of the VP by common noun objects is unrelated to Case licensing. As previously noted in Sect. 3.2, all internal arguments aside from pronouns and proper names vacate the VP, regardless of category. PP arguments also cannot remain inside the fronted VP, as the examples in $(82 \mathrm{a}-\mathrm{b})$ demonstrate.

$P P$ arguments must vacate the VP:

a. e a [vp vosa tiko] vei Jone ko Eroni. 3SG PST talk PROG to.PR Jone ART.PR Eroni 'Eroni talked to Jone.'

b. *e a [vp vosa vei Jone tiko] ko Eroni. 3SG PST talk to.PR Jone PROG ART.PR Eroni 'Eroni talked to Jone.'

The same can be observed with complement clauses, which also must appear after postverbal particles (83a-b).

$C P$ arguments must vacate the VP:

a. au [vP kila-a tiko] [CP ni o iko vuku].

1SG think-TR.N PROG C ART.PR 2SG smart

'I am thinking that you are smart.'

b. *au [vp kila-a [CP ni vuku ko Eroni] tiko].

1SG know-TR.N C smart ART.PR Eroni PROG

'I am thinking that Eroni is smart.'

There must then be a pressure independent of Case licensing that forces arguments of the verb to vacate the VP before it fronts. As discussed by Chung (2005) and Massam (2010), this problem in fact arises in many VP-fronting analyses and is independent of the DOM pattern found in Fijian.

One possibility is that this pressure is prosodic in nature, although a proper evaluation of this suggestion requires more detailed study of Fijian prosody. In particular, I propose that the Fijian verb has a requirement that it must be followed by a prosodically dependent element and not a prosodic phrase, like a PP, CP, or common noun with article. This is reminiscent of the constraint STRONG START, stated in (84). (See also Clemens 2014 for a prosodic account of VSO/VOS alternations in Niuean.)

STRONG START (Selkirk 2011):

A prosodic constituent optimally begins with a leftmost daughter constituent which is not lower in the prosodic hierarchy than the constituent that immediately follows. 
In short, STRONG START penalizes prosodic phrases that consist of a prosodic word followed by a prosodic phrase. As discussed, Fijian verbs form a prosodic phrase with the material that follows inside the fronted VP, including pronoun/proper name objects and postverbal particles. STRONG START is satisfied when the element that follows the verb is a pronoun, proper name, or postverbal particle, since these also represent prosodic words. If we assume that common noun objects, PP objects, and complement clause are always prosodic phrases, by virtue of their internal complexity, such objects would violate STRONG START if they remain inside the fronted VP.

One piece of evidence for a prosodic approach comes from the observation that material following a pronoun/proper name is sometimes permitted inside the fronted $\mathrm{VP}$, as long as the pronoun/proper name still immediately follows the verb. Pronouns can be modified by common nouns, in an appositive construction like (85a). In this construction, the common noun can appear in the fronted VP $(85 \mathrm{~b})$. Since the pronoun precedes the common noun object, it can form a prosodic phrase with the verb that satisfies STRONG START.

Common noun objects with pronouns precede postverbal particle:

a. e a [vp diri-ki $\mathbf{r a u}_{\mathrm{i}}$ na niu $\left.\mathrm{i}_{\mathrm{i}}\right]$ ko Eroni. 3SG PST crack-TR.PR 3DU ART.N coconut ART.PR Eroni 'Eroni cracked the coconuts (dual).'

b. e a [vP kau-ti [DP iratou na ilokoloko] mai] ko 3SG PST bring-TR.PR 3PAUC ART.N pillow DIR ART.PR

Eroni.

Eroni

'Eroni brought the pillows (paucal).'

A common noun can also appear inside the fronted VP if in a disjunctive phrase, as long as the pronoun or proper name is the first disjunct (86). ${ }^{36}$

Common noun in disjunct inside fronted VP:

iko a [vp rai-ci Eroni se na koli tiko].

2SG PST see-TR.PR Eroni or ART.N dog PROG

'You were seeing Eroni and the dogs.'

These facts are further evidence that common noun objects move out of the fronting VP for reasons that are independent of Case licensing, much like PP and CP arguments. The key property that distinguishes common nouns from other objects is that they are structurally reduced and so are caseless.

${ }^{36}$ It is also possible to have a long proper name in a fronted VP, in an example like (i).

(i) Long proper name in a fronted VP:

au [kau-ti Eroni Lomata mai].

1SG bring-TR.PR Eroni Lomata DIR

'I brought Eroni Lomata.'

If last names are analyzed as modifiers, as suggested by Matushansky (2008b), these facts can be viewed in a similar way. 


\subsection{Consequences for the theory of DOM}

The analysis of Fijian outlined here poses a problem for any approach to DOM that treats it purely as a positional difference or as a difference in overt case marking. One view of DOM, for example, is that it arises because objects higher in definiteness and animacy may undergo an additional operation of object raising (e.g. Diesing 1992; Bhatt and Anagnostopoulou 1996; Baker and Vinokurova 2010). The Fijian DOM pattern seems to provide strong evidence against the claim that differential object marking effects have their source exclusively in object movement.

At the same time, Fijian does provide some evidence for a link between definiteness and object movement, along the lines of Diesing (1992). As noted in the discussion of common nouns above, there is a correlation between syntactic position and the interpretation of common noun objects. In particular, a common noun object that has vacated the VP is interpreted as definite (87a), while an indefinite object is more typically expressed with noun incorporation (87b).

Noun incorporation used for indefinites:

a. e a kau-ta mai na ilokoloko ko Eroni.

3SG PST bring-TR.N DIR ART.N pillow ART.PR Eroni

'Eroni brought the pillows.'

b. e a kau ilokoloko ko Eroni.

3SG PST bring pillow ART.PR Eroni

'Eroni brought pillows.'

We can understand this pattern if definite common nouns undergo object shift, as argued by Diesing (1992). As a result, the Fijian facts do not undermine the idea that definiteness may require moving out of VP for interpretive reasons. But such movement cannot be the only source of DOM effects, because pronouns and proper names must remain low. ${ }^{37}$

The Fijian object marking pattern is also a counterexample to the idea that DOM universally involves additional marking on objects higher in definiteness and animacy. It seems to pose a problem for theories like Haspelmath's (2018), which treats DOM as a pressure to put overt marking on nominals which depart from prototypical associations of reference and thematic role. Similarly, Fijian presents a problem for approaches to DOM that relate it to pressures on the expression of case marking itself. In Aissen's (2003) account, for example, DOM is driven by conflicting constraints on the expression of case morphology, to avoid case marking where possible but provide overt case marking on marked objects. Since the Fijian DOM system involves no additional morphology on objects higher in definiteness, DOM cannot exclusively be about overt morphological asymmetries of this type.

What the Fijian facts provide evidence for is a broader approach to DOM, in which objects higher in definiteness and animacy must undergo an additional morphosyntactic process, which can manifest itself in different ways. One type

\footnotetext{
${ }^{37}$ That pronouns and proper names do not appear to have to escape the VP is a challenge for the Diesing view. One way to deal with this is to posit a covert operation of QR. Another possibility is that the inherent definiteness of such nominals allows them to be interpreted as definites in the VP.
} 
of theory that can capture this observation is one that assumes an asymmetry in Case licensing (e.g. Massam 2001; Danon 2006; Ormazabal and Romero 2013; Kalin 2018), such that some objects have an additional licensing need. As I have argued here, a Case licensing view provides a natural understanding of the range of strategies that can be used to create a DOM pattern.

Let me also briefly discuss the consequences of the current proposal for morphosyntactic effects associated with definiteness. As discussed above, I have cast the role of definiteness in Fijian as a difference in structural size between common nouns and proper names/pronouns. From this perspective, it is worth discussing whether a similar approach could work for other DOM patterns that make the same cut between pronouns/proper names and common nouns, such as Pitjantjatjara and Corsican (Bowe 1990; Neuburger and Stark 2014). As in Fijian, DOM in both languages is about definiteness and not animacy. In Pitjantjatjara, place names appear with the same case suffixes as other proper names, including the accusative (88a), as well as the pronoun/proper name suffixes for other cases, like the locative $-l a$ in (88b). ${ }^{38}$ In Corsican too, place names surface with the dative marker à (88c).

Place names marked like proper names in Pitjantjatjara and Corsican: ${ }^{39}$

a. Tilunkitja-ngka ngalku-la maa-paka-nu Ngarutjara-ku Tilunkitja-LOC eat-ANT.SS away-get.up-PST Ngarutjara-PURP para-ukali-ngu Anapala-nya. around-go.down-PST Ernabella-ACC

'We went on from Tilunkitja, having eaten there, and went down around Ngarutjara but avoided Ernabella.'

(Pitjantjatjara; Edwards 1994:152, glossing mine)

b. Minyma tjuta a-nu Docker River-la-kutu mingkul-ku. woman many go-PST Docker River-LOC.PR-ALL wild.tobacco-PURP 'The women went to Docker River for wild tobacco.'

(Pitjantjatajara; Langlois 2004:56)

c. Vinz, cù i so $600 \mathrm{omi}$, più un centu di a furtezza di Vinz with DET his 600 men plus one hundred from DET fortress of Calvi, più un centu di Corsi di l'-Algaiola, decide Calvi plus one hundred of Corsicans from DET-Algaiola decide d'occupà à Calinzana. to.occupy DAT Calinzana 'Vinz, with his 600 men, plus one hundred from the fortress of Calvi, plus one hundred Corsicans from Algaiola, decides to occupy Calinzana.' (Corsican; Neuburger and Stark 2014:376)

\footnotetext{
${ }^{38}$ In Pitjantjatjara, as in Fijian, the interrogative pronoun ngana ('who') is treated as a pronoun/proper name, while nyaa ('what') is marked like a common noun (Langlois 2004:54). A similar pattern seems to be found in Corsican. Neuburger and Stark (2014:378) note that universal quantifiers like tutti ('all') are DOM-marked if they refer to humans, but not otherwise.

${ }^{39}$ Note that, in Western Desert orthography, underlining represents retroflex consonants.
} 
Interestingly, there is some evidence for structural reduction in Pitjantjatjara, since Pitjantjatjara common nouns are not marked for number or definiteness. This similarity with Fijian could be further support for a link between structural reduction and differences between pronouns/proper names and common nouns. However, Legate (2008) argues that some case splits in Pama-Nguyan language are morphological and not syntactic in nature and this possibility would have to be ruled out for Pitjantjatjara. In addition, in Corsican, common nouns display no clear evidence of structural reduction. As in other Romance languages, common nouns surface with number marking and can combine with a definite article. I leave it as an open question then whether differences in structural size are responsible for all patterns that make the same cut between pronouns/proper names and common nouns.

\subsection{The role of adjacency in other DOM patterns}

If licensing by adjacency can be one of the mechanisms involved in DOM, we expect to find similar patterns in other languages, with familiar variation in which types of objects require additional Case licensing. I discuss some similar patterns in other Oceanic languages in this section. In addition, I discuss the proposal that an operation of morphological merger lies behind instances of pseudo-noun incorporation (Levin 2015).

Pearce $(2000,2001)$ points out that Iaai has a DOM pattern that is similar to Fijian. Like Fijian, Iaai distinguishes between pronoun and proper name objects and common nouns. Iaai lacks the article alternation found in Fijian, but requires pronoun and proper name objects to immediately follow the verb (89a-b), before any aspectual particles. Common noun objects, on the other hand, must occur after aspectual particles $(89 \mathrm{c}-\mathrm{d})$.

Iaai pronoun/proper name objects are verb-adjacent:

a. a-me ka kuc Pou thibut.

3SG-PROC SIMUL hit Pou COMPL

'And he hit Pou.'

b. oge oo u dhö.

1SG see 2 SG PUNCT

'I've found you.'

c. a-me an $\underline{\text { dhö }}$ jee wââ.

3SG-PROC eat PUNCT PL fish

'S/he ate the fish.'

d. a-me uny jut anyin ûxaaû.

3SG-PROC take.off COMPL his shirt

'S/he is taking off his shirt.'

(Pearce 2000:25-26)

Pearce $(2000,2001)$ analyzes the adjacency effect in $(89 a-b)$ as a process of Dincorporation, much like the proposal pursued here. Evidence for this word formation process comes from the observation that pronoun and proper name objects trigger allomorphy on the preceding verb. Many Iaai verbs have distinct forms depending on 
whether they combine with a common noun or pronoun/proper name object, like the verb kot ('hit/kill') (90a-c). ${ }^{40}$

\section{Pronoun/proper name objects trigger allomorphy in Iaai:}
a. a-me kot tep.
3SG-PROC hit rat
'S/he is killing the rat.'
b. a-me kuc u.
3SG-PROC hit 2SG
'S/he is hitting you.'
c. a-me kuc Poou.
3SG-PROC hit Poou
'S/he is hitting Poou.'

(Pearce 2000:23)

Otsuka (2000) observes that Tongan has a related pattern, except that only pronouns undergo incorporation. Like Fijian, Tongan is verb-initial. In addition, subjects and objects appear with ergative/absolutive case markers (91a). Otsuka notes that object pronouns, and not other objects, can be without their case marker when immediately following the verb $(91 \mathrm{~b}-\mathrm{c})$.

Pronouns in Tongan can appear verb-adjacent without case marker:
a. Na'e'ave'e Sione'a au.
PST take ERG Sione ABS $1 \mathrm{SG}$
'Sione took me.'
b. Na'e 'ave au 'e Sione.
PST take $1 \mathrm{SG}$ ERG Sione
'Sione took me.'
c. *Na'e 'ave Mele'e Sione.
PST take Mele ERG Sione
'Sione took Mele.'

(Otsuka 2000:149)

To capture this, Otsuka posits an optional rule that right-adjoins pronouns to the verb. We can understand this incorporation process as Local Dislocation at PF, as in Fijian. The only difference between Fijian and Tongan is that Tongan limits this process to pronominal objects. ${ }^{41}$ As noted by Aranovich (2013), similar patterns to the Tongan one can be found in Rotuman and Western Fijian languages (Kikusawa 2001; Kissock 2003).

The existence of such patterns provides additional evidence that differential object marking can be based around adjacency. All languages in this small sample limit this type of licensing to pronoun/proper name objects. What this restriction could reveal is that Local Dislocation of this type is limited to heads. The idea that licensing by

\footnotetext{
${ }^{40}$ As Pearce discusses, these allomorphy effects appear to have their origins in an $-i$ suffix present with pronoun/proper name objects, triggering vowel raising and palatalization. Synchronically, however, the patterns are no longer phonologically predictable.

${ }^{41}$ Another difference is that absolutive case appears to be available to all objects, which is difficult to square with the caselessness I posited for common noun objects in Fijian. One option is that the absolutive morpheme is a default marker of some sort and not a reflex of Case licensing.
} 
adjacency might be restricted to objects that are sufficiently small may also allow us to make sense of the idea that Local Dislocation plays a role in cases of pseudo-noun incorporation. As first noted by Massam (2001), a number of languages have DOM patterns in which objects lower in definiteness and animacy must appear immediately adjacent to the verb, as in the Niuean alternation in $(92 \mathrm{a}-\mathrm{b})$, without having undergone syntactic incorporation.

\section{Adjacency in Niuean:}

a. Takafaga tūmau nī e ia e tau ika hunt always EMPH ERG he ABS PL fish 'He is always hunting fish.'

b. Takafaga ika n̄ a ia hunt fish EMPH ABS he 'He is always hunting fish.'

(Niuean; Massam 2001:157)

Levin (2015) develops an Local Dislocation analysis of such patterns, arguing that a DOM pattern of this type can arise when a structurally reduced object is licensed by Local Dislocation, in much the same fashion as I proposed for Fijian. As Levin (2015: Sect. 3.1) discusses in detail, objects that undergo pseudo-noun incorporation are always structurally reduced in some sense, disallowing DP-level material and sometimes more. We can make sense of this if Local Dislocation is limited to nominals that are sufficiently small, like pronouns, proper names and reduced nouns. ${ }^{42}$

A question that arises, however, is why, in pseudo-noun incorporation constructions, objects lower in definiteness and animacy require Case licensing, given the approach to DOM I adopted above. As Keine and Müller (2008) argue, there are other cases of DOM in which there is no difference in licensing, but a difference in the type of Case licensing strategy. In Finnish, for example, DOM involves a distinction between genitive/accusative case, on the one hand, and partitive case, on the other. If this is right, then some DOM patterns do not involve a difference in the presence or absence of licensing, but a difference in the type of strategy that is used. This type of view could work for Niuean: objects that undergo pseudo-noun incorporation meet the Case Filter through morphological merger, and objects that do not are licensed by absolutive case. One piece of evidence in favor of this perspective is the observation that objects lower in definiteness or animacy are not universally subject to verb-adjacency requirements. Kalin (2018) points out that, in Senaya, non-specific objects (which do not trigger object agreement) occupy exactly the same positions as other objects and can be separated from the verb $(93 a-b)$.

\section{Nonagreeing objects in Senaya are not verb-adjacent:}

a. Āna ō ksūta [ta d-on yāle] maxw-an-ā.

I that book to GEN-those children show.IMPF-S.1FS-L.3FS 'I (will) show that book to the children.'

\footnotetext{
${ }^{42}$ But note that, in Fijian, it is important that structurally reduced nouns cannot undergo Local Dislocation. One option might be to attribute this difference between Fijian and Niuean to the presence of $n a$ with common nouns. If $n a$ is an instance of $n$, it could be that it is impossible to omit $n a$ for independent reasons, since doing so would leave the root uncategorized.
} 

b. Āna xa ksūta [ta d-on yāle] maxw-an.
I a book to GEN-those children show.IMPF-S.1FS
'I (will) show a book to the children.'
(Senaya; Kalin 2018:125)

The existence of cases like the Senaya one alongside the Niuean one suggest a view of DOM in which some DOM patterns are characterized by the presence or absence of Case licensing, and some by the presence of two different licensing strategies.

\section{On the partial pronominal argument analysis}

Much previous work on Fijian has analyzed it as a partial pronominal argument language (Schütz and Nawadra 1972; Alderete 1998; Aranovich 2013; Schütz 2014), in the sense of Jelinek (1984) and Baker (1988). In this approach, proper names and pronouns are different from common nouns in that they appear as true objects of the verb, as the complement of V. Common noun objects, however, are analyzed as adjoined phrases, co-indexed with an incorporated pronoun. The facts presented here demonstrate that the Fijian DOM pattern is not about a distinction between base-generated and dislocated phrases, since the DOM effect holds even in derived environments. A consequence of my analysis then is that it is not necessary to allow a mechanism of partial polysynthesis. In this section, I briefly discuss the partial polysynthesis analysis, as developed in Alderete (1998) and Aranovich (2013), and show that it cannot account for object marking across a clause boundary.

Much previous research on Fijian adopts a partial polysynthesis analysis of the unusual differential object marking pattern (Schütz and Nawadra 1972; Alderete 1998; Aranovich 2013). This approach to the object alternation exploits the morphological alternation between the $-\mathrm{Ci}$ and $-\mathrm{Ca}$ suffix. The $-\mathrm{Ca}$ suffix is usually decomposed into $-\mathrm{Ci}+a$, where $-a$ represents a reduced form of the 3rd person singular koya. There is historical evidence that $-\mathrm{Ca}$ derives from $-\mathrm{Ci}-\mathrm{a}$ in Proto-Fijian (see Pawley and Sayaba 1971 and Clark 1974, for example). In addition, the idea that the $-\mathrm{Ca}$ suffix contains an object pronoun is evident in the fact that the - $C a$ suffix may also be used in isolation, with the object interpreted as a pronominal (94).

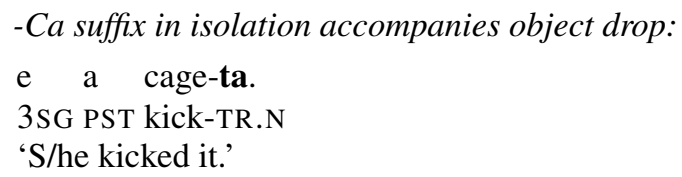

On the basis of this decomposition, it is proposed that, when common nouns co-occur with the $-\mathrm{Ca}$ suffix, they are doubled by an object clitic (95).

Common noun objects doubled by object clitic:

e a rai-ca na koli $\mathbf{i}_{\mathbf{i}}$ ko Eroni.

3SG PST see-TR.N ART.N dog ART.PR Eroni

'Eroni saw the dog.' 
Such an analysis draws a parallel between objects and subjects. Common noun subjects are always cross-referenced by a preverbal subject clitic, such as the 3rd person singular $e$ in (95). These subject clitics are also frequently used in isolation (96a-b).

Subject clitics may be doubled or occur in isolation:

a. au dau vosa.

1SG HAB speak

'I always talk.'

b. era vosa vaka Viti.

3PL speak VAKA Fiji

'They speak Fijian.'

Although Fijian common nouns are number-neutral, their number is indicated on the doubling subject clitic $(97 \mathrm{a}-\mathrm{b})$.

Doubling subject clitic may indicate number of common noun subject:

a. $\mathbf{e}_{\mathbf{i}}$ a rai-ca na koli na gone.

3SG PST see-TR.N ART.N dog ART.N child

'The child saw the dog.'

b. era ${ }_{i}$ a rai-ca na koli na gone.

3PL PST see-TR.N ART.N dog ART.N child

'The children saw the dog.'

A similar option seems to be available with common noun objects. A common noun object may appear alongside an unreduced 3rd person pronoun as well, signaling the number of the common noun $(98 \mathrm{a}-\mathrm{b})$. In this construction, the verb appears with the $-\mathrm{C} i$ suffix and the pronoun is immediately verb-adjacent, like other pronoun objects.

Doubling object pronoun may indicate number of common noun object:

a. e rai-ci ira na koli $_{i}$ ko Eroni.

3SG see-TR.PR 3PL ART.N dog ART.PR Eroni

'Eroni sees the dogs.'

b. e a diri-ki $\mathbf{r a u}_{\mathbf{i}}$ na niu $\mathbf{n i}_{\mathrm{i}}$ ko Eroni.

3SG PST crack-TR.PR 3DU ART.N coconut ART.PR Eroni

'Eroni cracked the coconuts (dual).'

These facts can be interpreted to suggest an analysis of the $-\mathrm{Ci} / \mathrm{Ca}$ in which common noun objects are always doubled by an object clitic. The object clitic always follows the suffix $-\mathrm{Ci}$, but, with the 3 rd person singular clitic, a special reduced form appears, $-C a$. In this view, the representation of (99a) is really (99b).

Representation of -Ca suffix:

a. e a rai-ca na koli $\mathbf{i}_{\mathbf{i}}$ ko Eroni.

3SG PST see-TR.N ART.N dog ART.PR Eroni

'Eroni saw the dog.'

b. e a rai-ci+koya $a_{i}$ na koli $_{i}$ ko Eroni.

3SG PST see-TR.PR+3SG ART.N dog ART.PR Eroni 
We can adopt this view in a DOM analysis as well, with the assumption that the object marker on the verb is deleted when Local Dislocation takes place. This deletion suppresses the $-a$ suffix, resulting in a $-C i$ suffix. ${ }^{43}$

The presence of a doubling object pronoun has also been used to treat Fijian as a polysynthetic language (Schütz and Nawadra 1972; Alderete 1998; Aranovich 2013; Schütz 2014), in which these subject and object clitics represent the true subject and object, in the sense of Jelinek (1984) and Baker (1988). In this approach, the postverbal nominals that appear following postverbal particles represent optional dislocated phrases that are adjoined to TP and co-indexed with a clitic. In other words, subjects and common noun objects are base-generated as adjuncts, co-indexed with the incorporated object in the $-C a$ suffix. This analysis is schematized in $(100 a-b) .{ }^{44}$

(100) Partial polysynthesis analysis of Fijian:

a. $\left[\begin{array}{lll}\mathrm{TP}_{\mathrm{i}} & \text { a } & \text { rai-ca }\end{array}\right]$ [na koli $]_{\mathrm{k}}\left[\begin{array}{ll}\mathrm{ko} & \text { Eroni }\end{array}\right]_{\mathrm{i}}$. 3SG PST see-TR.N ART.N dog ART.PR Eroni 'Eroni saw the dog.'

b.

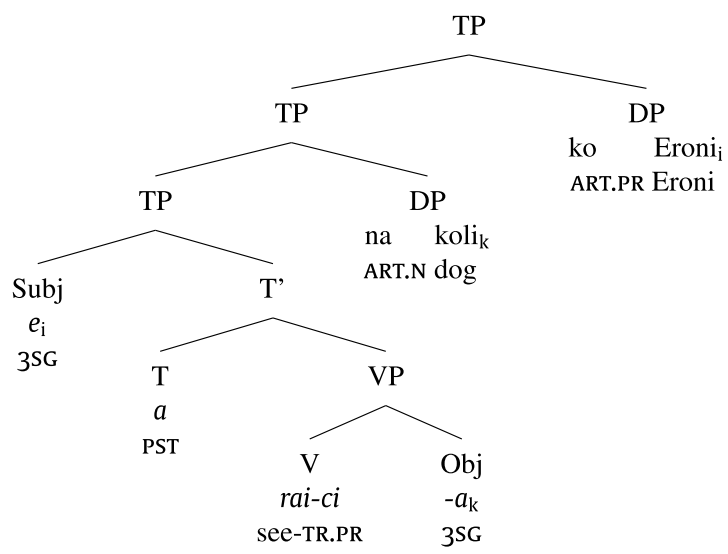

This approach explains why subjects and common noun objects must appear peripherally, after postverbal particles, on the assumption that such particles mark the right edge of the verbal domain. In addition, this view explains why pronoun objects seem to be subject to an adjacency requirement. In this analysis, the verb-adjacent position is just the ordinary complement position of a true object. Also, the article omission pattern can be viewed as a difference between adjoined phrases and true arguments: only dislocated phrases are introduced by the article ko/na. Finally, as Aranovich points out, this polysynthetic approach provides a straightforward account for the alternation between VSO and VOS word order. Since subjects and objects are adjoined phrases, they should be able to adjoin in any order.

\footnotetext{
${ }^{43}$ Another option is to treat the $-\mathrm{Ci} / \mathrm{Ca}$ as a case of allomorphy, triggered by the presence of a pronoun/proper name object.

${ }^{44}$ Alderete (1998) only treats objects as optional adjoined phrases, and not subjects. This is derived from a semantic treatment of the DOM effect. I will not discuss this particular version of the partial polysynthesis account, since it runs into the same issues.
} 
This polysynthetic perspective runs into an issue with proper names, however, since these do not behave like common nouns in object position. Like common noun subjects, proper name subjects are doubled by a preverbal subject clitic. But, as discussed, in object position, proper names appear verb-adjacent and surface without their article, just like pronouns (101a-b).

Proper name objects must be verb-adjacent:
a. e a kau-ti
Eroni.
3SG PST bring-TR.PR Jone DIR ART.PR Eroni
'Eroni brought Jone.'
b. *e a kau-ti mai Jone ko Eroni.
3SG PST bring-TR.PR DIR Jone ART.PR Eroni
'Eroni brought Jone.'

To accommodate the behavior of proper names, a polysynthetic approach must treat Fijian as a partially polysynthetic language, in which proper names can act as true objects as well and must reside in the complement position of V as well. Aranovich's analysis accomplishes this by incorporating a restriction on the complement position of $\mathrm{V}$ that restricts the types of objects that are allowed. Specifically, Aranovich adopts the constraint in (102), which bans all objects that are not higher than human on the person/animacy scale in (103). ${ }^{45}$

\section{Fijian Transitivity Constraint (Aranovich 2013:492):}

In Fijian, the features of the VP complement must outrank the feature [human] in the person/animacy scale.

\section{Person/animacy scale (Aranovich 2013:492): \\ pronominal $>$ proper $>$ human $>$ animate $>$ inanimate}

Such a constraint allows proper names to function as true objects in addition to pronouns. Note also that the constraint in (102) must differ from the constraint assumed to restrict the subject position, since proper name subjects cannot appear in the same position as preverbal subject clitics. To accommodate the divergence between subjects and objects, this perspective on Fijian syntax must then assume that subjects obey an even stricter requirement and can only be pronominal in nature.

The facts presented in Sect. 4 present an argument against the partial polysynthesis analysis. Partial polysynthesis cannot account for the fact that the adjacency effect found with pronouns and proper names surfaces in derived environments as well, as in (104).

$$
\begin{aligned}
& \text { Adjacency with pronouns/proper names in derived environment: } \\
& \text { au kila-i } \quad \text { CP cei e a rai-ca na cava]. } \\
& \text { 1SG know-TR.PR who 3SG PST see-TR.N ART.N what } \\
& \text { 'I know who saw what.' }
\end{aligned}
$$

\footnotetext{
${ }^{45}$ Alderete (1998) adopts a semantic analysis. He suggests that, while pronouns and proper names are all of type $e$, common nouns are all of type $<e t, t>$ and so must QR to combine with a transitive verb. He proposes that Fijian lacks the requisite operation of QR, so that only a right-dislocated structure allows for the introduction of a common noun.
} 
In (104), the pronoun cei is not a base-generated argument of the higher verb and does not reside in its complement position. The difference between pronoun and proper name objects and common nouns can then not be attributed to Aranovich's Transitivity Constraint in this context. Object marking differences in Fijian cannot be a distinction between dislocated phrases and true arguments. An analysis based on Local Dislocation, in contrast, accounts for the distribution of DOM in Fijian, and the possibility of licensing under adjacency across a clause boundary. As a consequence, it may not be necessary to admit the possibility of partial pronominal argument languages into the grammar.

\section{Conclusion}

This paper has argued that Fijian has a crosslinguistically unusual pattern of differential object marking, in which objects higher in definiteness or animacy show reduced marking and appear in a lower position. This pattern arises because pronoun/proper name objects are licensed by adjacency with the verb, specifically an operation of morphological merger at PF (Levin 2015; Branan 2017; cf Stowell 1981; Ackema and Neeleman 2003). These facts suggest a perspective on DOM in which objects higher in definiteness and animacy have an additional Case licensing need (e.g. Massam 2001; Danon 2006; Ormazabal and Romero 2013; Kalin 2018). In this approach, Fijian DOM is no different from other DOM patterns in that an additional licensing strategy is used with objects higher in animacy/definiteness. What is different is only that Fijian makes use of an operation of morphological merger rather than an additional case marker or agreement. In this way, the Fijian facts provide support for the idea that nominals are subject to the Case Filter (Vergnaud 2008/1977).

Acknowledgements My thanks to David Adger, Raúl Aranovich, David Hall, Claire Halpert, Daniel Harbour, Laura Kalin, Theodore Levin, David Pesetsky, Masha Polinsky, and Michelle Yuan for comments and discussion, as well as audiences at NELS 47 and LAGB 2017. I am indebted to Eroni Lomata and Koini Cokanasiga for sharing their language with me. My thanks also to Rochelle Wild and everyone in the Spring 2017 field methods class LIN312.

Open Access This article is distributed under the terms of the Creative Commons Attribution 4.0 International License (http://creativecommons.org/licenses/by/4.0/), which permits unrestricted use, distribution, and reproduction in any medium, provided you give appropriate credit to the original author(s) and the source, provide a link to the Creative Commons license, and indicate if changes were made.

\section{References}

Ackema, Peter, and Ad Neeleman. 2003. Context-sensitive spell-out. Natural Language and Linguistic Theory 21: 681-735.

Adger, David. 2000. Feature checking under adjacency and VSO clause structure. In The nature and function of syntactic categories, ed. Robert Borsley, 79-100. Cambridge: Academic Press.

Aissen, Judith. 2003. Differential object marking: Iconicity vs. economy. Natural Language and Linguistic Theory 21: 435-483.

Alderete, John. 1998. Canonical types and noun phrase configuration in Fijian. In UCLA Occasional Papers in Linguistics 21: Recent papers in Austronesian linguistics, ed. Matt Pearson, 19-44. Los Angeles: UCLA. 
Aranovich, Raúl. 2013. Transitivity and polysynthesis in Fijian. Language 89: 465-500.

Aranovich, Raúl. 2015. Fijian weak quantification as head-internal relativization. In Austronesian Formal Linguistics Association (AFLA) 21, eds. Amber Camp, Yuko Otsuka, Claire Stabile, and Nozomi Tanaka, Asia-Pacific Linguistics, 1-14.

Arms, David. 1974. Transitivity in standard Fijian. PhD diss., University of Michigan.

Baker, Mark. 1988. Incorporation: A theory of grammatical function changing. Chicago: University of Chicago Press.

Baker, Mark, and Nadya Vinokurova. 2010. Two modalities of case assignment: Case in Sakha. Natural Language and Linguistic Theory 28: 593-642.

Barrie, Michael, and Éric Mathieu. 2016. Noun incorporation and phrasal movement. Natural Language and Linguistic Theory 34: 1-51.

Bhatt, Rajesh, and Elena Anagnostopoulou. 1996. Object shift and specificity: Evidence from ko-phrases in Hindi. Paper presented at the 32th Regional Meeting of the Chicago Linguistic Society. Chicago.

Bossong, Georg. 1991. Differential object marking in Romance and beyond. In New analyses in Romance linguistics, eds. Douglas A. Kibbee and Dieter Wanner, 143-170. Amsterdam: Benjamins.

Bowe, Heather. 1990. Categories, constituents, and constituent order in Pitjantjatjara, an Aboriginal language of Australia. London: Routledge.

Branan, Kenyon. 2017. Licensing with case: Evidence from Kikuyu. Ms., MIT.

Branigan, Phil, and Marguerite MacKenzie. 2002. Altruism, Ā-movement, and object agreement in Innuaimûn. Linguistic Inquiry 33: 385-407.

Chomsky, Noam. 1981. Lectures on Government \& Binding. Dordrecht: Foris.

Chomsky, Noam. 2001. Derivation by phase. In Ken Hale: A life in language, ed. Michael Kenstowicz, 1-52. Cambridge: MIT Press.

Chung, Sandra. 2005. What fronts? On the VP-raising account of verb-initial order. In Verb first: On the syntax of verb-initial languages. eds. Andrew Carnie, Heidi Harley, and Sheila Ann Dooley, 10-29. Amsterdam: Benjamins.

Clark, Ross. 1974. Transitivity and case in Eastern Oceanic languages. Oceanic Linguistics 12: 559-605.

Clemens, Lauren. 2014. Prosodic noun incorporation and verb-initial syntax. PhD diss., Harvard University,

Clemens, Lauren, and Jessica Coon. 2018. Deriving verb-initial word order in Mayan. Language 94: 237280 .

Collins, James. 2017. Samoan predicate initial word order and object positions. Natural Language and Linguistic Theory 35: 1-59.

Compton, Richard, and Christine Pittman. 2010. Word-formation by phase in Inuit. Lingua 120: 21672192.

Comrie, Bernard. 1989. Language universals and linguistic typology. Chicago: University of Chicago Press.

Danon, Gabi. 2006. Caseless nominals and the projection of DP. Natural Language and Linguistic Theory 24: 977-1008.

Deal Amy Rose. 2016. Covert hyperraising to object. Handout from Northeast Linguistic Society (NELS) 47. Amherst: UMass.

Diesing, Molly. 1992. Indefinites. Cambridge: MIT Press.

Dixon, Robert M. W. 1979. Ergativity. Language 55: 59-138.

Dixon, Robert M. W. 1988. A grammar of Boumaa Fijian. Chicago: University of Chicago Press.

Edwards Bill. trans. 1994. Mutuka Nyakunytja: Seeing a motorcar. A Pitjantjatjara text. Related by Jacky Tjurupulu Wangkanytja. Aboriginal History 19: 145-158.

Embick, David, and Rolf Noyer. 2001. Movement operations after syntax. Linguistic Inquiry 32: 555-595.

Haspelmath, Martin. 2018. Role-reference associations and the explanation of argument coding splits. Ms., Universität Leipzig

Jelinek, Eloise. 1984. Empty categories, case, and configurationality. Natural Language and Linguistic Theory 2: 39-76.

Kalin, Laura. 2018. Licensing and differential object marking: The view from Neo-Aramaic. Syntax 21: 112-159.

Keine, Stefan, and Gereon Müller. 2008. Differential argument encoding by impoverishment. In Scales, eds. Marc Richards and Andrej L. Malchukov. 83-136. Leipzig: Universität Leipzig.

Kikusawa, Ritsuko. 2001. Rotuman and Fijian case-marking strategies and their historical development. Oceanic Linguistics 40: 85-111.

Kissock, Madelyn. 2003. Transitivity and objecthood in Rotuman. Oceanic Linguistics 42: 144-160. 
Langlois, Annie. 2004. Alive and kicking: Areyonga Teenage Pitjantjatjara. Pacific Linguistics.

Legate, Julie Anne. 2008. Morphological and abstract Case. Linguistic Inquiry 39: 55-101.

Levin, Theodore. 2015. Licensing without case. PhD diss., MIT.

Marantz, Alec. 1991. Case and licensing. In Eastern States Conference on Linguistics (ESCOL) 91, eds. Germán Westphal, Benjamin Ao, and Hee-Rahk Chae, 234-253. Ithaca: Cornell Linguistics Club.

Massam, Diane. 1985. Case theory and the projection principle. PhD diss., MIT.

Massam, Diane. 2001. Pseudo noun incorporation in Niuean. Natural Language and Linguistic Theory 19: 153-197.

Massam, Diane. 2010. Deriving inverse order. In Austronesian and theoretical linguistics, eds. Raphael Mercado, Eric Potsdam, and Lisa deMena Travis, 271-296. Amsterdam: Benjamins.

Matushansky, Ora. 2008a. A case study of predication. In Studies in formal Slavic linguistics: Contributions from FDSL 6.5, eds. Franc Marušič and Rok Žaucer, 213-239. Bern: Peter Lang.

Matushansky, Ora. 2008b. On the linguistic complexity of proper names. Linguistics and Philosophy 21: 573-627.

Medeiros, David. 2013. Hawaiian VP-remnant movement: A cyclic linearization approach. Lingua 127: 72-97.

Milner, George. 1972. Fijian grammar. Suva: Government Press.

Neuburger, Kathrin Anne, and Elisabeth Stark. 2014. Differential object marking in Corsican: Regularities and triggering factors. Linguistics 52: 365-389.

Ormazabal, Javier, and Juan Romero. 2013. Differential object marking, case and agreement. Borealis: An International Journal of Hispanic Linguistics 2: 221-239.

Otsuka, Yuko. 2000. Ergativity in Tongan. PhD diss., University of Oxford.

Ott, Dennis. 2008. Aspects of Fijian noun-phrase structure. Ms., Harvard University.

Pawley, Andrew, and Timoci Sayaba. 1971. Fijian dialect divisions: Eastern and Western Fijian. Journal of the Polynesian Society 80: 405-436.

Pearce, Elizabeth. 2000. Object agreement and incorporation in Iaai. In 2000 Conference of the Australian Linguistic Society, eds. Keith Allan and John Henderson. http://www.als.asn.au.

Pearce, Elizabeth. 2001. Lexical feature-driven incorporation in two Oceanic languages: Iaai and Fijian. The Linguistic Review 18: 265-288.

Polinsky, Maria, and Eric Potsdam. 2001. Long-distance agreement and topic in Tsez. Natural Language and Linguistic Theory 3: 583-646.

Potsdam, Eric. 2009. Austronesian verb-initial languages and wh-question strategies. Natural Language and Linguistic Theory 27: 737-771.

Potsdam, Eric, and Maria Polinsky. 2011. Questions and word order in Polynesian. In Topics in Oceanic morphosyntax. 27: 121-153.

Rackowski, Andrea, and Lisa Travis. 2000. V-initial languages: X or XP movement and adverb placement. In The syntax of verb-initial languages, eds. Andrew Carnie and Eithne Guilfoyle, 117-142. Oxford: Oxford University Press.

Sabel, Joachim. 2011. Deriving linear order in OV/VO languages: Evidence from Oceanic languages. In Topics in Oceanic morphosyntax, eds. Claire Moyse-Faurie and Joachim Sabel, 27-64. Berlin: de Gruyter.

Schütz, Albert. 2014. Fijian reference grammar. Honolulu: Pacific Voices.

Schütz, Albert, and Tevita Nawadra. 1972. A refutation of the notion of "passive" in Fijian. Oceanic Linguistics 11: 88-109.

Scott, N. C. 1948. A study in the phonetics in Fijian. Bulletin of the School of Oriental and African Studies 12: 737-752.

Selkirk, Elisabeth. 2011. The syntax-phonology interface. In The handbook of phonological theory, eds. John Goldsmith, Jason Riggle, and Alan Yu, 435-484. Hoboken: Wiley-Blackwell.

Sheehan, Michelle, and Jenneke van der Wal. 2016. Do we need abstract Case? In 33rd West Coast Conference on Formal Linguistics (WCCFL), eds. Kyeong-min Kim, Pocholo Umbal, Trevor Block, Queenie Chan, Tanie Cheng, Kelli Finney, Mara Katz, Sophie Nickel-Thompson, and Lisa Shorten, 351360. Somerville: Cascadilla Proceedings Project.

Siewierska, Anna. 2001. On the argument status of cross-referencing forms: Some problems. Revista Canaria de Estudios Ingleses 42: 215-236.

Silverstein, Michael. 1976. Hierarchy of features and ergativity. In Grammatical categories in Australian languages, ed. R. M. W. Dixon, 112-171. Canberra: Australian Institute of Aboriginal Studies.

Stowell, Tim. 1981. Origins of phrase structure. PhD diss., MIT. 
Vergnaud, Jean-Roger. 2008. Letter to Noam Chomsky and Howard Lasnik on filters and control. In Foundational issues in linguistic theory, eds. Robert Freidin, Carlos P. Otero, and Maria Luisa Zubizarreta. Cambridge: MIT Press. April 17, 1977.

Wang, Ruoan. 2018. Fijian possession, MA thesis, Queen Mary University of London. Zwart, Jan-Wouter. 2011. The syntax of Dutch. Cambridge: Cambridge University Press.

Zyman, Erik. 2018. On the driving force for syntactic movement. PhD diss., UC Santa Cruz. 